\title{
The Effect of Urban Density and Vegetation Cover on the Heat Island of a Subtropical City
}

\author{
SARAH CHAPMAN \\ School of Earth and Environmental Sciences, University of Queensland, St Lucia, Queensland, Australia \\ MARCUS THATCHER \\ CSIRO Marine and Atmospheric Research, Aspendale, Victoria, Australia
}

ALVARO SALAZAR

School of Earth and Environmental Sciences, University of Queensland, St Lucia, Queensland, Australia

JAMES E. M. WATSON

School of Earth and Environmental Sciences, University of Queensland, St Lucia, Queensland, Australia, and Global Conservation Program, Wildlife Conservation Society, Bronx, New York

Clive A. MCAlpine

School of Earth and Environmental Sciences, University of Queensland, St Lucia, Queensland, Australia

(Manuscript received 1 November 2017, in final form 3 August 2018)

\begin{abstract}
The urban heat island (UHI) has a negative impact on the health of urban residents by increasing average temperatures. The intensity of the UHI effect is influenced by urban geometry and the amount of vegetation cover. This study investigated the impact of urban growth and loss of vegetation cover on the UHI in a subtropical city (Brisbane, Australia) during average and extreme conditions using the Conformal Cubic Atmospheric Model, run at a 1-km spatial resolution for 10 years. The average nighttime temperature increase was $0.7^{\circ} \mathrm{C}$ for the "Medium Density" urban growth scenario and $1.8^{\circ} \mathrm{C}$ for the "No Vegetation" scenario. During two widespread extreme heat events, the mean maximum increase in urban temperatures above the Control was between $2.2^{\circ}$ and $3.8^{\circ} \mathrm{C}$ in the No Vegetation scenario and between $0.3^{\circ}$ and $1.6^{\circ} \mathrm{C}$ in the Medium Density urban growth scenario. The results are similar to previous findings for temperate cities, with the intensity of the UHI effect higher at night and during winter than during the day and summer. Vegetation cover had the strongest impact on temperatures, more so than building height and height/width ratio. Maintaining and restoring vegetation, therefore, is a key consideration in mitigating the urban heat island. The large temperature increases found in this study, particularly during extreme heat events, shows the importance of reducing the UHI for protecting the health of urban residents, and this should be a priority in urban landscape planning and design.
\end{abstract}

\section{Introduction}

The urban heat island (UHI) effect is a prominent example of how human modification of the land surface affects the local and regional climate (Pielke et al. 2016). However,

\footnotetext{
${ }^{a}$ Additional affiliations: Departamento de Biología, Facultad de Ciencias, Universidad de La Serena, La Serena, and Instituto de Ecología y Biodiversidad, Universidad de Chile, Ñuñoa, Chile.
}

Corresponding author: Sarah Chapman, s.chapman@uq.edu.au the geographic focus has been mainly on temperate cities rather than tropical or subtropical cities (Arnfield 2003; Roth 2007; Karam et al. 2010; Stewart 2011). This is an important limitation because tropical and subtropical cities are growing faster than cities at higher latitudes (Roth 2007; Seto et al. 2012). Previous work in tropical and subtropical cities has shown that the UHI intensity tends to be lower than in temperate cities, which may be due to differences in anthropogenic heating, surface moisture, building materials, or number of heating/cooling degree days (Wienert and Kuttler 2005; Roth 2007). 
In temperate cities, summer-winter differences are important determinants of the magnitude of the heat island effect, while wet-dry seasonal differences are more important in tropical and subtropical cities (Arnfield 2003). Given the projected high rates of future urban growth in tropical and subtropical cities, and that temperatures and heat stress are already high for most of the year (Hyatt et al. 2010), understanding the UHI effect in these cities is important.

The UHI occurs when urban areas are warmer than rural areas and is caused by the conversion of the land surface to urban uses (Arnfield 2003). The UHI increases as cities grow in size and density (Arnfield 2003). On average, the UHI is $2^{\circ} \mathrm{C}$, but can exceed $8^{\circ} \mathrm{C}$ under conditions of low wind speed and cloud cover (Gedzelman et al. 2003; Chang et al. 2007; Wilby 2008; Sharifi and Lehmann 2014). The main mechanisms influencing the UHI are the reduction in evapotranspiration due to a loss of vegetation, increase in anthropogenic heat release from human activity (i.e., vehicle use, heating and cooling of buildings), changes in albedo from buildings, and trapping of radiation in the "urban canyon" (Oke 1982; Arnfield 2003). The magnitude of the UHI is affected by both urban expansion and increasing density of urban land use. Increased density includes increased building heights, reduced height/width ratio of streets to buildings, and reduced vegetation fraction. The geographic expansion of the urban area tends to increase the spatial extent of the UHI effect with little effect on its intensity, whereas increasing urban density tends to increase the intensity of the UHI effect (Coutts et al. 2008; Adachi et al. 2014; Chapman et al. 2017).

Urban residents are more vulnerable to heat stress during heat waves due to the UHI effect; however, heat waves may also intensify a preexisting heat island (Luber and McGeehin 2008; Hajat et al. 2010; Li and Bou-Zeid 2013; Li et al. 2015). This effect has not been found in all cities, with the intensity of the heat island decreasing during heat waves in some cities (Scott et al. 2018). The interaction between the UHI and heat waves is an area of current research, and is not well understood. Some authors have suggested mechanisms through which heat waves can intensify the UHI, such as through changes to weather and reduced evapotranspiration in urban areas (Li and Bou-Zeid 2013; Li et al. 2015). As temperature increases, evaporation increases with sufficient water availability; however, urban areas have limited water available for evapotranspiration, so evapotranspiration may not increase in a heat wave in urban areas as much as in rural areas ( $\mathrm{Li}$ et al. 2015). As a consequence, latent heat flux may increase more in rural areas during a heat wave than in urban areas ( $\mathrm{Li}$ et al. 2015). For longduration heat waves, however, this mitigating effect may reverse if vegetation loses too much water to evapotranspiration in the beginning of the heat wave, and as a consequence has limited water available for evapotranspiration in the later stages of the heat wave (Yunusa et al. 2015; Ward et al. 2016). Heat waves can also be associated with highpressure anticyclones, which are associated with low wind speeds which tend to increase the UHI effect (Oke 1982; Li and Bou-Zeid 2013). The reduced evapotranspiration and low wind speeds may act synergistically, not only increasing the absolute urban and rural temperatures, but also increasing the differences between urban and rural temperatures and the associated heat stress (Li and Bou-Zeid 2013). There is evidence that heat waves and the UHI effect interact synergistically to enhance the UHI in some cities, though not all (i.e., Scott et al. 2018), and ongoing research is needed to fully understand this drivers of this interaction.

A main component of the UHI is the reduction in vegetation cover in urban areas (Oke 1982; Grimmond and Oke 1991; Loughner et al. 2012). With less vegetation cover (grass and trees), there is less evapotranspiration, and energy is partitioned more into sensible rather than latent heat (Oke 1982). Trees also affect temperatures within cities through shading and lowering of wind speeds (Heisler 1977; Spronken-Smith and Oke 1998; Loughner et al. 2012). During the day, areas with tall trees will be cooler than urban areas and open parks with low tree cover due to higher rates of evapotranspiration and deeper shade cover. During the evening, tall trees will cool more slowly than open areas due to a lower sky-view factor (Spronken-Smith and Oke 1998, 1999). A park with high tree cover tends to be cooler during the night time than the surrounding urban area due to starting the evening with a lower temperature, whereas an open park tends be hotter during the day but cool more rapidly after sunset (Spronken-Smith and Oke 1998, 1999; Potchter et al. 2006). In summary, grass and trees both have the potential to reduce temperatures in urban areas, with treed parks being more effective during the day, and open grassy areas potentially being more effective at night.

Previous UHI studies have focused mostly on expansive forms of urban growth, rather than densification (Chapman et al. 2017). Expansion mainly increases the area affected by the UHI, while densification tends to increase the intensity of the UHI (Coutts et al. 2008; Adachi et al. 2014). Although spatial expansion has been the most common form of urban growth, there has been widespread adoption of policies that promote more compact cities (Chan and Yung 2004; Seto et al. 2011). Densification of urban areas is common in Europe, while in the United States, city densities have declined over time despite policies to reduce sprawl (Broitman and Koomen 2015). In Australia, many urban planning policies aim to limit urban expansion in preference to 


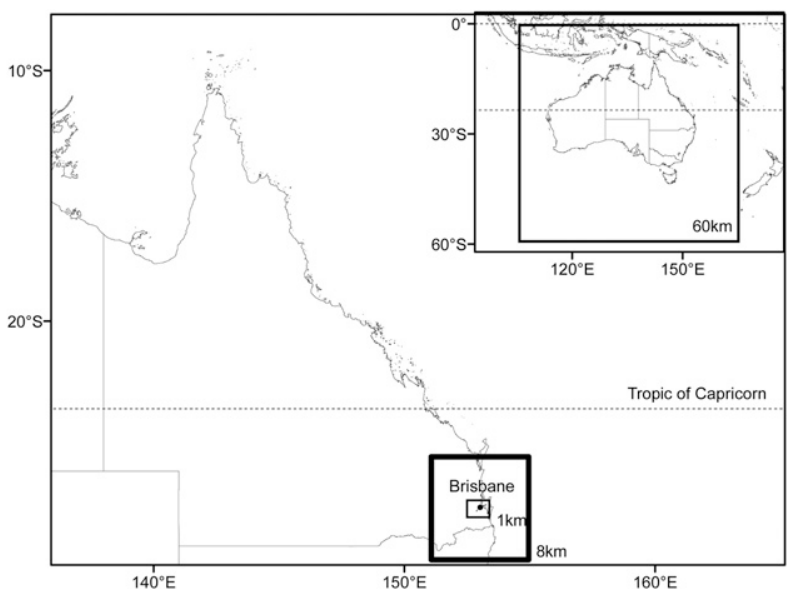

FIG. 1. Location of the study area (Brisbane, Australia) and the domains for 1 - and $8-\mathrm{km}$ model resolution. The inset map shows the domain for $60-\mathrm{km}$ resolution. Dashed lines show the Tropic of Capricorn and the equator.

higher-density infill (Brisbane City Council 2014; NSW Department of Planning and Environment 2014; City of Melbourne 2016). While urban expansion is an important process affecting the UHI, the prevalence of compact, high-density city planning policies means it is also important to explore the impact of urban densification on the UHI.

Here, we examine the impact of urban growth on the temperatures experienced by a subtropical city during both average temperature conditions and extreme high-temperature conditions. We conducted two highresolution climate modeling experiments of the impact of contrasting land-cover scenarios on the climate of Brisbane, a subtropical city in eastern Australia. The first scenario involved reducing vegetation cover to zero, while the second scenario involved a reduction in vegetation cover and an increase in building height by increasing the urban density in approximately half of the urban area. We examined the effect on the UHI for both average and extreme heat conditions to determine if the change in the magnitude of the effect was amplified during hot weather.

\section{Methods}

\section{a. Study area}

Brisbane is the third most populous city in Australia, with 1.9 million people (see Fig. 1). It has a subtropical climate $\left(27.4698^{\circ} \mathrm{S}, 153.02151^{\circ} \mathrm{E}\right)$ with summer-dominant rainfall (Bureau of Meteorology 2017). Mean monthly temperatures range from $21.7^{\circ}$ to $28.5^{\circ} \mathrm{C}$ and in the last 10 years there have been on average 43 days a year when temperature exceeded $30^{\circ} \mathrm{C}$ (Bureau of Meteorology 2017). Over the next 30 years, urban population growth is
TABLE 1. Model schemes used in CCAM.

\begin{tabular}{|c|c|}
\hline Physical options & Schemes \\
\hline Cloud microphysics & $\begin{array}{l}\text { Liquid and ice-water microphysics scheme } \\
\text { of Rotstayn (1997). Snow and graupel } \\
\text { scheme of Lin et al. (1983) }\end{array}$ \\
\hline $\begin{array}{l}\text { Convective } \\
\text { parameterization }\end{array}$ & $\begin{array}{l}\text { Mass-flux cumulus convection scheme } \\
\text { (McGregor 2003; McGregor and Dix } \\
\text { 2008) }\end{array}$ \\
\hline Radiatio & $\begin{array}{l}\text { Geophysical Fluid Dynamics Laboratory } \\
\text { parameterization for shortwave and } \\
\text { longwave radiation (Schwarzkopf and } \\
\text { Fels 1991; Schwarzkopf and Ramaswamy } \\
\text { 1999) }\end{array}$ \\
\hline Gra & Chouinard et al. (1986) \\
\hline Bou & $\begin{array}{l}\text { Local Richardson number (McGregor } \\
\text { et al. 1993) and nonlocal vertical mixing } \\
\text { (Holtslag and Boville 1993) }\end{array}$ \\
\hline Land surface model & $\begin{array}{l}\text { CABLE land surface scheme (Kowalczyk } \\
\text { et al. 2006) }\end{array}$ \\
\hline Urban model & ATEB (Thatcher and Hurley 2012) \\
\hline
\end{tabular}

expected to continue at $1.4 \%-3.1 \%$ per annum, and most urban development will be via densification rather than geographic expansion of the urban area (Australian Bureau of Statistics 2013; Brisbane City Council 2014).

\section{b. Model configuration}

In this study, we used the CSIRO conformal cubic atmospheric model (CCAM) to run high-resolution (1-km grid cell) climate simulations over Brisbane City. CCAM is an atmospheric global model developed on a conformal grid (McGregor and Dix 2001, 2008). Using the Schmidt transformation, CCAM can run in a stretched-grid mode which allows high-resolution simulation over selected regions (McGregor and Dix 2008). For our experiments, the model was first run with a quasi-uniform global resolution of $100 \mathrm{~km}$ using a C96 grid. This experiment used biascorrected sea surface temperatures from ACCESS1.0, a global climate model developed by CSIRO and the Australian Bureau of Meteorology (Bi et al. 2013). The bias correction method is described by Hoffmann et al. (2016) and is designed to improve the mean and interannual variability in climate variables, as compared with noncorrected SSTs. The model was then run in stretched grid mode and downscaled to 60,8 , and then $1 \mathrm{~km}$ resolution over the following regions: $0^{\circ}-60^{\circ} \mathrm{S}, 105^{\circ}-165^{\circ} \mathrm{E} ; 25.5^{\circ}-29.5^{\circ} \mathrm{S}, 151^{\circ}-$ $155^{\circ} \mathrm{E}$; and $27.2^{\circ}-27.8^{\circ} \mathrm{S}, 152.7^{\circ}-153.5^{\circ} \mathrm{E}$ (see Fig. 1). We used a global stretched $\mathrm{C} 48$ grid and extracted data from the high-resolution area (1-km domain), which used $48 \times$ 48 grid points. A total of 27 vertical model levels were used, ranging from $20 \mathrm{~m}$ to $35 \mathrm{~km}$, with 10 levels in the first $1000 \mathrm{~m}$. The orography data used in CCAM have a 250-m resolution over Australia and were provided by Geoscience Australia.

The model physics schemes are listed in Table 1. CCAM includes the Australian Town Energy Budget 
TABLE 2. Summary of land-cover variables associated with each scenario.

\begin{tabular}{llc}
\hline \hline Scenario name & \multicolumn{1}{c}{ Description } & Land cover \\
\hline Control & Control & Uses 2001 MODIS land cover with the addition of the CBD \\
No Vegetation & Reduce vegetation fraction in urban areas to 0\% & $\begin{array}{c}\text { Same land cover as Control, but the green-space fraction for } \\
\text { each urban category in ATEB was reduced to 0\% }\end{array}$ \\
Medium Density & $\begin{array}{c}\text { Increase urban density from low to medium in } \\
\text { approximately one-half of area }\end{array}$ & $\begin{array}{c}\text { Based on 2001 MODIS land cover, with inner half of the } \\
\text { Brisbane urban area changed from low density to medium } \\
\text { density }\end{array}$ \\
\hline
\end{tabular}

(ATEB) model for urban areas. ATEB is based on the Town Energy Budget model and has been updated to reflect the Australian context; idealized air conditioners have been parameterized, the urban vegetation component has been altered to better reflect the vegetation in Australian suburbs, and the model now includes consideration of two canyon walls facing easterly and westerly directions (Masson 2000; Thatcher and Hurley 2012). ATEB has previously been used to model urban climates, including with mitigation measures, such as increasing albedo and vegetation, in Australian cities (Chen et al. 2014; Luhar et al. 2014; Ren et al. 2014; Chen et al. 2015).

\section{c. Experimental design}

The experiments (see Table 2 for description) were designed to evaluate the effect of vegetation and urban land cover on temperatures (see Fig. 2 for the land cover for each scenario). The three contrasting simulations were 1) a control, 2) a zero vegetation cover run, and 3) a run with approximately one-half of the urban area converted from low to medium density. These scenarios are referred to as Control, No Vegetation, and Medium Density.

The land-cover maps of all scenarios were based on the Moderate Resolution Imaging Spectroradiometer (MODIS) 2001 land-cover data, with the IGBP classification scheme (Global Land Cover Facility 2018). In addition, two new urban categories were added: urbanhigh and urban-medium (see Table 3 for an explanation of the parameters associated with these categories).

For the Control scenario, the only change to land cover was the addition of the central business district (CBD) as a high-density area. For this scenario, the low-density urban
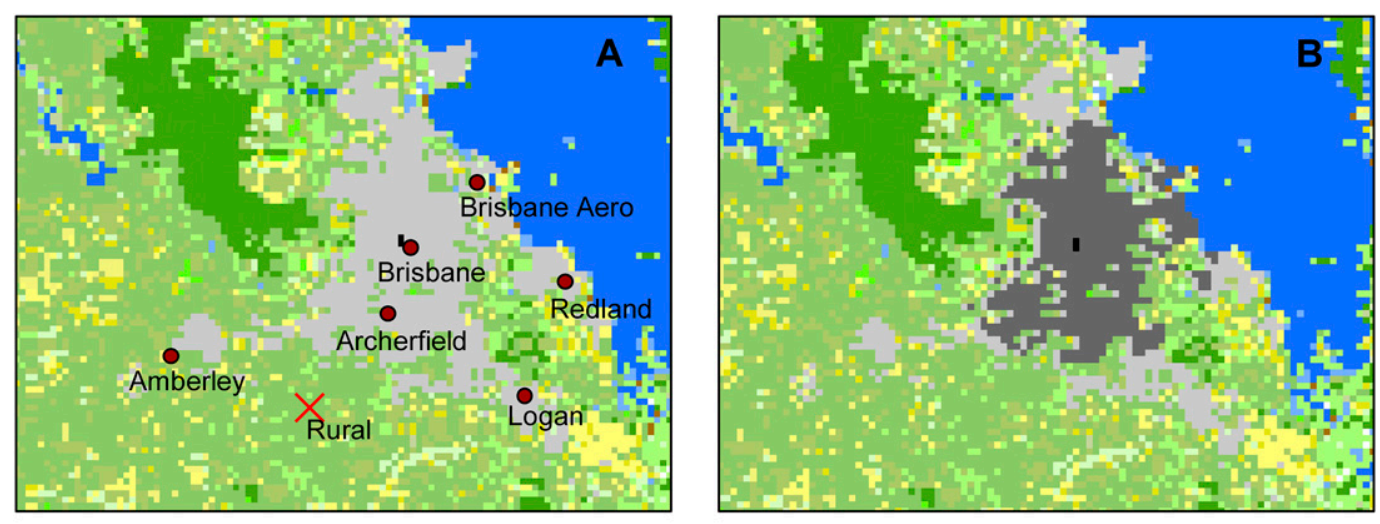

\section{Legend}

\begin{tabular}{|c|}
\hline Evergreen broadleaf forest \\
\hline Deciduous broadleaf forest \\
\hline Mixed forest \\
\hline Closed shrublands \\
\hline Open shrublands \\
\hline Woody savannas \\
\hline
\end{tabular}
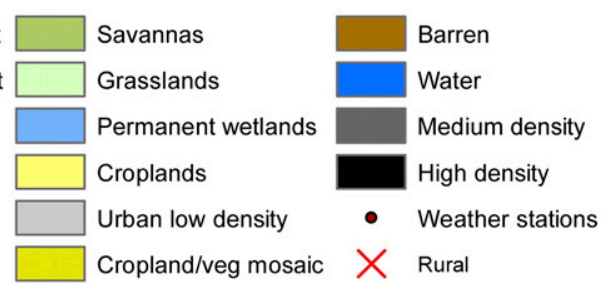

FIG. 2. Land cover for each of the scenarios: (a) Control and No Vegetation and (b) Medium Density. For No Vegetation, the same map as the Control scenario was used but the vegetated fraction in the urban areas was set to zero. Red points show the location of weather stations used to validate the model predictions. The red times sign shows the location of the "Rural" point used for comparing urban and rural scenario results. 
TABLE 3. Characteristics for the urban categories (high, medium, and low) used in ATEB.

\begin{tabular}{lccc}
\hline \hline \multicolumn{1}{c}{ Category } & Urban high & Urban medium & Urban low \\
\hline Building height $(\mathrm{m})$ & 18 & 8 & 6 \\
Building fraction & $65 \%$ & $46 \%$ & $45 \%$ \\
Green space fraction & $5 \%$ & $34 \%$ & $45 \%$ \\
Height/width ratio & 2 & 0.6 & 0.4 \\
Roof albedo & 0.2 & 0.2 & 0.2 \\
Wall albedo & 0.3 & 0.3 & 0.3 \\
Road albedo & 0.1 & 0.1 & 0.1 \\
Vegetation roughness & 0.1 & 0.1 & 0.1 \\
$\quad$ length & & & \\
\hline
\end{tabular}

area covered $900 \mathrm{~km}^{2}$, and the CBD area covered $2 \mathrm{~km}^{2}$. The Control scenario was designed to represent the current Brisbane land cover and act as a comparator for the Medium Density and No Vegetation scenarios.

In the Medium Density scenario, approximately onehalf of the low-density urban land cover was converted to medium density (see Fig. 2). Converting from low- to medium-density urban land cover increases building heights by $2 \mathrm{~m}$, reduces the amount of green space by $11 \%$, reduces building fraction by $1 \%$, and increases the height/ width ratio by 0.2 . This scenario models the effect of changing building height, height/width ratio, vegetation fraction, and building fraction on urban temperatures.

The No Vegetation experiment represented an urban landscape with no vegetation cover and tested the impact of removing vegetation cover on temperatures. This scenario had the same land-cover categories as the Control (see Fig. 2); however, the green-space fraction was changed in the urban-low and urban-high categories to $0 \%$.

The parameters for each urban category in ATEB were based on measurements from Melbourne, an Australian city with a temperate climate, and are shown in Table 3 (Coutts et al. 2007). The urban categories correspond to the Urban Climate Zones developed by Oke (2004). Urban-high corresponds to urban climate zone 3 (highly developed, medium density), and urban-medium and urban-low correspond to zone 5 (medium density, lowdensity suburban) (Coutts et al. 2007). Green-space fraction refers to in-canyon vegetation, primarily represented as 1-m shrubs, and is based on a big-leaf model as described in Thatcher and Hurley (2012).

The land-cover differences between each scenario and the Control at specific points are detailed in Table 4. Land cover at the Rural point remained the same for all scenarios. For No Vegetation, all urban locations saw reductions in vegetation. For the Medium Density scenario, land cover changed at Brisbane City and Archerfield.

The average land-cover change associated with the No Vegetation scenario was a reduction in green space of $45 \%$. In the low-density area, which covers $99.7 \%$ of the
TABLE 4. Changes in land cover for each scenario (No Vegetation and Medium Density) at each location in comparison with the Control.

\begin{tabular}{lcc}
\hline \hline Location & No Vegetation & Medium Density \\
\hline Brisbane & $\begin{array}{c}\text { Vegetation fraction reduced } \\
\text { from } 45 \% \text { to } 0 \%\end{array}$ & $\begin{array}{c}\text { Low to medium } \\
\text { density }\end{array}$ \\
Archerfield & $\begin{array}{c}\text { Vegetation fraction reduced } \\
\text { from } 45 \% \text { to } 0 \%\end{array}$ & $\begin{array}{c}\text { Low to medium } \\
\text { density }\end{array}$ \\
Logan & Vegetation fraction reduced & Remained low \\
& from $45 \%$ to $0 \%$ & density \\
Rural & No change & No change \\
\hline
\end{tabular}

urban area in the Control, green-space fraction was reduced from $45 \%$ to $0 \%$. In the high-density area, which covers the remaining $0.3 \%$ of the Control urban area, the green-space fraction was reduced from $5 \%$ to $0 \%$. In the Medium Density scenario, over half of the lowdensity area was changed to medium density, while highdensity areas and the remaining low-density areas were left unchanged. This corresponds to an average increase in building height over the entire urban area of $1.3 \mathrm{~m}$, an average increase in building fraction of $0.65 \%$, a decrease in vegetated fraction of $7.2 \%$ and an increase in height/width ratio of 0.13 .

Each scenario was run for 10 years $(2000-10)$ over summer, November-February, with November being discarded after acting as a month of spinup for each summer (December-February). At $1 \mathrm{~km}$, CCAM has a time step of $20 \mathrm{~s}$, as does ATEB. The scenario outcomes were compared using seasonal average temperature and during an extreme heat event. Extreme heat events were defined as three or more consecutive days with average temperature above the 97.5 th percentile of average rural air temperature. In addition, sensitivity experiments were conducted using ATEB to determine how sensitive the urban model was to changes in vegetation fraction, roughness length, building height and height/width ratio. The results of the sensitivity experiments are shown in appendix A.

\section{Model validation and UHI calculation}

The ability of the model to reproduce air temperatures in summer was evaluated by comparing the Control monthly average, minimum, and maximum temperature with observational data from six Bureau of Meteorology weather stations (see Table 5, Fig. 2). The observational monthly average temperature was calculated based on 3-hourly data provided by the Bureau of Meteorology. All stations except Redland and Logan had hourly data available at 3-h intervals. Redland and Logan only had data available for 0900 and 1500 local time (LT), and so they were not used in the calculation of bias for average temperature. Observational monthly 
TABLE 5. Bias of minimum, maximum, and average temperature ( $T_{\min }, T_{\max }$, and $T_{\text {avg }}$ ) as calculated between the Control and weather observation data from 2000 to 2010 . The weather stations with their identification numbers are Amberley (040004), Archerfield Airport (040211), Brisbane City (040913), Brisbane Airport (040842), Logan City Water Treatment Plant (040854), and Redland (040265). An asterisk indicates stations with data available only at 0900 and 1500 LT.

\begin{tabular}{lrrr}
\hline \hline \multicolumn{1}{c}{ Station } & \multicolumn{1}{c}{$T_{\min }$} & $T_{\max }$ & $T_{\text {avg }}$ \\
\hline Amberley & -0.69 & 1.94 & 0.55 \\
Archerfield & 0.78 & 1.90 & 1.55 \\
Redland* & 2.04 & 1.29 & \\
Brisbane Airport & 0.94 & 1.52 & 1.35 \\
Logan* & 0.51 & 1.96 & \\
Brisbane City & 0.35 & 1.69 & 1.25 \\
Mean & 0.66 & 1.72 & 1.12 \\
\hline
\end{tabular}

minimum and maximum data were calculated based on daily minimum and maximum data from the Bureau of Meteorology. The weather station data were also used to calculate the UHI.

The average summer temperature of the model was $1.12^{\circ} \mathrm{C}$ warmer than observations, based on average monthly temperature. The minimum temperature was $0.66^{\circ} \mathrm{C}$ warmer, while maximum temperature was $1.72^{\circ} \mathrm{C}$ warmer. Redland, a coastal location, had the highest bias with the minimum temperature $2.04^{\circ} \mathrm{C}$ too warm. The Brisbane City station had the lowest bias in minimum temperature of $0.35^{\circ} \mathrm{C}$.

The UHI was based on 3-hourly weather station data from 2000 to 2010 and was calculated as the difference between an urban point, Brisbane City weather station, and a rural point, the average of temperatures at Brisbane Airport and Amberley. Brisbane Airport and Amberley are the most rural of the available weather stations; however, they are located on the urban fringe, rather than being truly rural. Furthermore, Brisbane Airport is close to the coast and Amberley is $50 \mathrm{~km}$ inland and has a higher elevation than Brisbane City. Given neither is an ideal rural station, we have used an average of the temperatures at both stations as the rural temperature for the purposes of calculating the UHI. The average UHI from 2000 to 2010 was $0.8^{\circ} \mathrm{C}$. The UHI intensity was highest at night and lowest during the day, becoming a cool island in the afternoon (see Fig. 3). The UHI intensity was highest in winter and in the dry season, with an average of $1.4^{\circ} \mathrm{C}$, and lowest in summer, with an average of $0.4^{\circ} \mathrm{C}$.

\section{Results}

\section{a. Overview}

In the following sections, the results of the two scenarios of urban growth are first compared to the Control

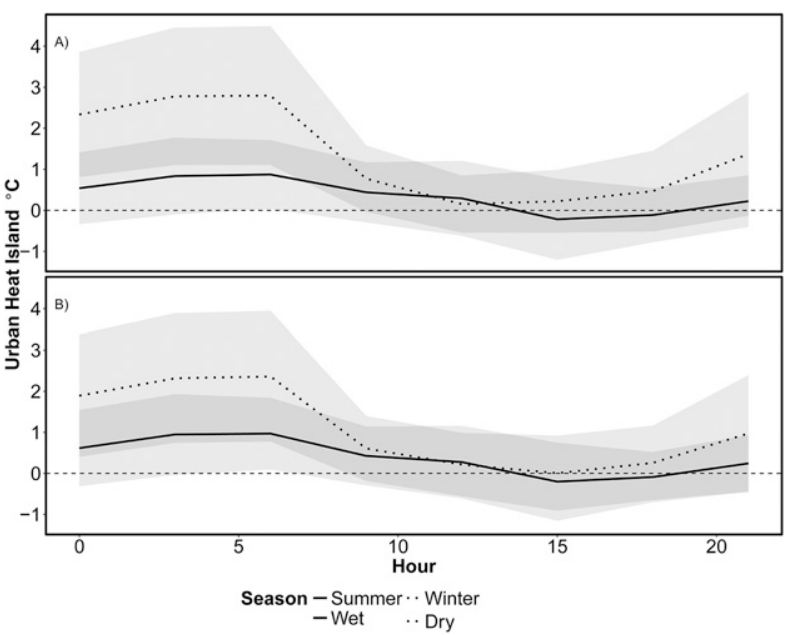

FIG. 3. The seasonal UHI, calculated as the difference between Brisbane City and the average of Amberley and Brisbane Airport, based on weather station observation data from 2000 to 2010, for (a) summer/winter, (b) wet (November-March) and dry (AprilOctober) seasons. The shaded area shows 1 standard deviation.

scenario using seasonal data. The scenarios are then compared to the Control across the entire study area using temperature, wind speed, relative humidity, and latent and sensible heat flux. Next, the number and duration of extreme heat events for each scenario are presented, followed by the number of hot days and nights per summer for each scenario. The UHI is then calculated using model data and compared to the UHI calculated using observational data. Last, the hourly variation in the components of the energy budget (latent and sensible heat flux, net radiation and storage) for each scenario is presented and used to explain the variation in temperature between the two land-cover scenarios and the Control.

\section{b. Change in temperature between scenarios based on seasonal temperature}

The changes in temperatures for each land-cover scenario were compared at four locations: Brisbane City, Archerfield and Logan weather stations, and one rural location (Fig. 2, Table 4). The changes in average summer temperature between the Control and the scenarios are shown in Table 6. The statistical significance of the difference between the average seasonal temperature of the scenarios and the Control was compared using the Kruskal-Wallis test because the assumption of normality was not met.

The largest temperature increases occurred at night when vegetation cover was reduced to $0 \%$ (see Fig. 4). The No Vegetation scenario resulted in increases in average temperature in urban locations of $0.8^{\circ}-0.9^{\circ} \mathrm{C}$ above the Control. Nighttime temperatures increased for No Vegetation in urban locations by $1.3^{\circ}-1.8^{\circ} \mathrm{C}$. Significant 
TABLE 6. The average difference in model temperatures between the two land-cover scenarios and the Control for all austral summers (DJF) for 2000-10. Here, two asterisks indicates significance level $p \leq 0.05$ and a single asterisk indicates $p \leq 0.1$. The Kruskal-Wallis test was used because of a lack of normality. Standard deviation is shown in parentheses.

\begin{tabular}{|c|c|c|c|c|c|c|}
\hline \multirow[b]{2}{*}{ Location } & \multicolumn{3}{|c|}{ No Vegetation - Control } & \multicolumn{3}{|c|}{ Medium Density - Control } \\
\hline & Avg & Min & Max & Avg & Min & Max \\
\hline Brisbane City & $0.99 *(0.09)$ & $1.83 * *(0.20)$ & $0.44(0.17)$ & $0.20(0.06)$ & $0.69 *(0.15)$ & $-0.09(0.14)$ \\
\hline Archerfield & $0.94 *(0.08)$ & $1.58 * *(0.14)$ & $0.40(0.21)$ & $0.15(0.07)$ & $0.45(0.09)$ & $-0.12(0.16)$ \\
\hline Logan & $0.86 *(0.09)$ & $1.36 * *(0.12)$ & $0.50(0.13)$ & $-0.03(0.14)$ & $0.01(0.11)$ & $-0.05(0.24)$ \\
\hline Rural & $0.10(0.28)$ & $0.14(0.13)$ & $-0.02(0.50)$ & $-0.04(0.27)$ & $0.00(0.09)$ & $-0.08(0.48)$ \\
\hline
\end{tabular}

changes in temperature occurred only where land cover was changed; for No Vegetation this was all the urban points, and for Medium Density, land cover changed at the Brisbane City weather station location. The increase in temperature at Archerfield was not significant for the Medium Density scenario. Increases in urban density had a smaller effect on temperatures than reducing vegetation cover, and the Medium Density scenario resulted in an increase of $0.69^{\circ} \mathrm{C}$ for nighttime temperatures.

\section{c. Change in temperature between land-cover scenarios across the study area}

Similar patterns of temperature change are shown for the entire Brisbane region (Fig. 5). Statistically significant changes in minimum temperature occurred within urban areas and for the No Vegetation scenario. For the No Vegetation scenario, minimum temperatures increased by $1^{\circ}-2^{\circ} \mathrm{C}$, while for the Medium Density scenario temperatures increased by up to $1^{\circ} \mathrm{C}$. There was

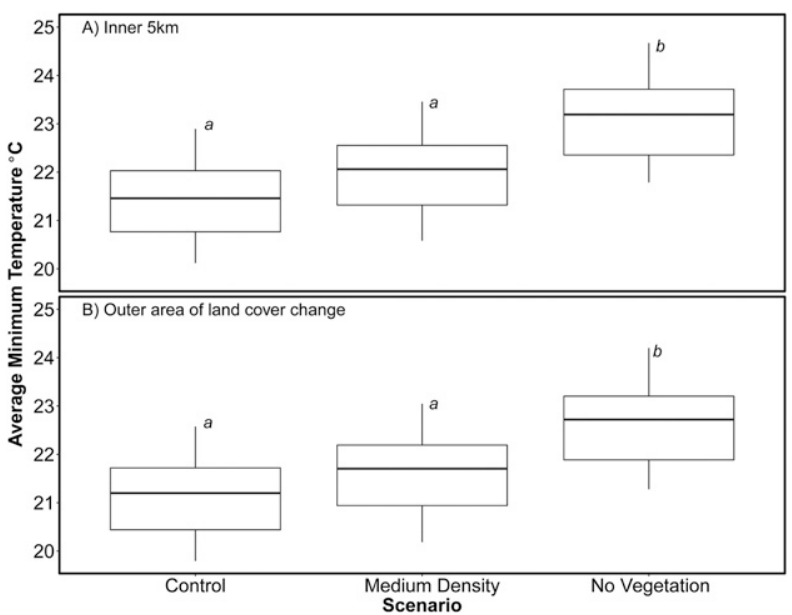

FIG. 4. CCAM seasonal mean minimum temperature ( \pm standard deviation, indicated by the whiskers) for each land-cover scenario between 2000 and 2010 (a) within approximately $5 \mathrm{~km}$ of the city center and (b) for the outer urban area ( $>5 \mathrm{~km}$ from CBD) that changed in the Medium Density scenario. The letter "a" indicates that the change in minimum temperature was not significant at $p<0.05 \%$, and " $b$ " indicates a significant change in minimum temperature. very little significant change in maximum temperature. Sensible and latent heat flux again had the most change within the urban area where land cover changed. Latent heat flux decreased in the urban areas for both scenarios, with the biggest decrease occurring for No Vegetation. Sensible heat flux increased for both scenarios.

There was a minor decrease in relative humidity in both scenarios, more so in the No Vegetation scenario (Fig. 5, row 5). Ten-meter wind speed decreased slightly in urban areas where land cover changed in the Medium Density scenario, and increased slightly in the No Vegetation scenario (Fig. 5, row 6). The decrease in relative humidity in the No Vegetation scenario is explained by the increase in temperature (Fig. 5, rows 1 and 2) and the decrease in latent heat flux (Fig. 5, row 3), both of which would act to decrease relative humidity. The increase in temperature results in an increase in the water vapor capacity of the air and decreasing relative humidity, while the decrease in latent heat flux means less evaporation and less water availability. The change in wind speed in both scenarios is explained by a change in surface roughness; higher buildings in the Medium Density scenario increase surface roughness, decreasing wind speed, while the reduction in vegetation in No Vegetation decreases surface roughness, increasing wind speed.

\section{d. Extreme heat events}

The duration and number of extreme heat events increased for both land-cover scenarios, but more so for the No Vegetation scenario. Extreme heat events were defined as events of 3 or more days with average daily temperature above the 97.5th percentile of average temperature for the Control Rural point, which was $30^{\circ} \mathrm{C}$. Over the entire 10 -yr period, extreme events were 3 times more common in the No Vegetation scenario than in the Control. There was little difference in the number of extreme heat events between the Control and Medium Density scenarios; however, for the Brisbane City weather station location, the extreme events lasted longer than in the Control. For the Control, extreme events of 5 days only occurred at the Rural point and Archerfield, while in the Medium Density scenario, these 
Control

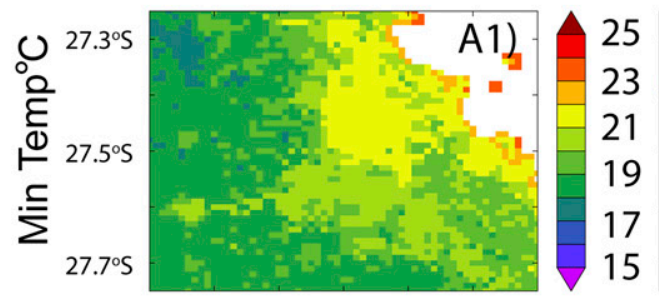

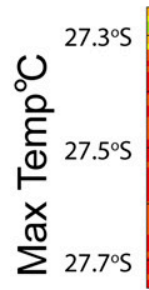
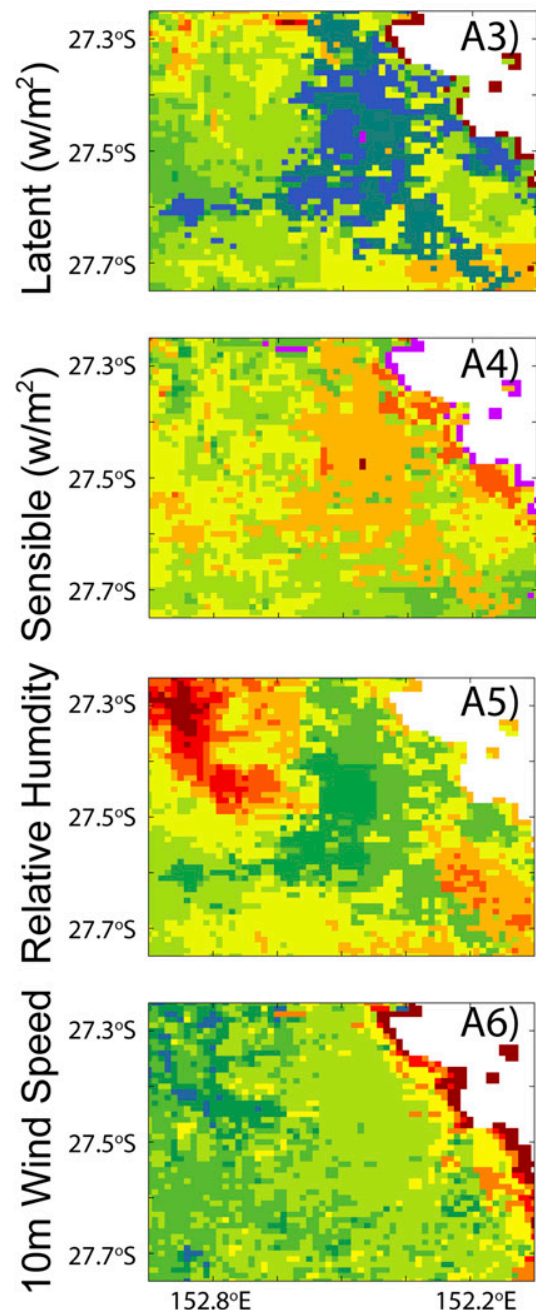

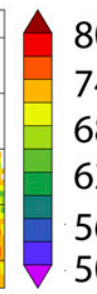

Medium Density

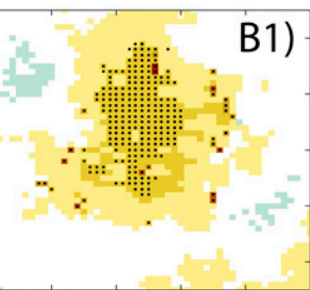

B2)

35
33
31
29
27
25
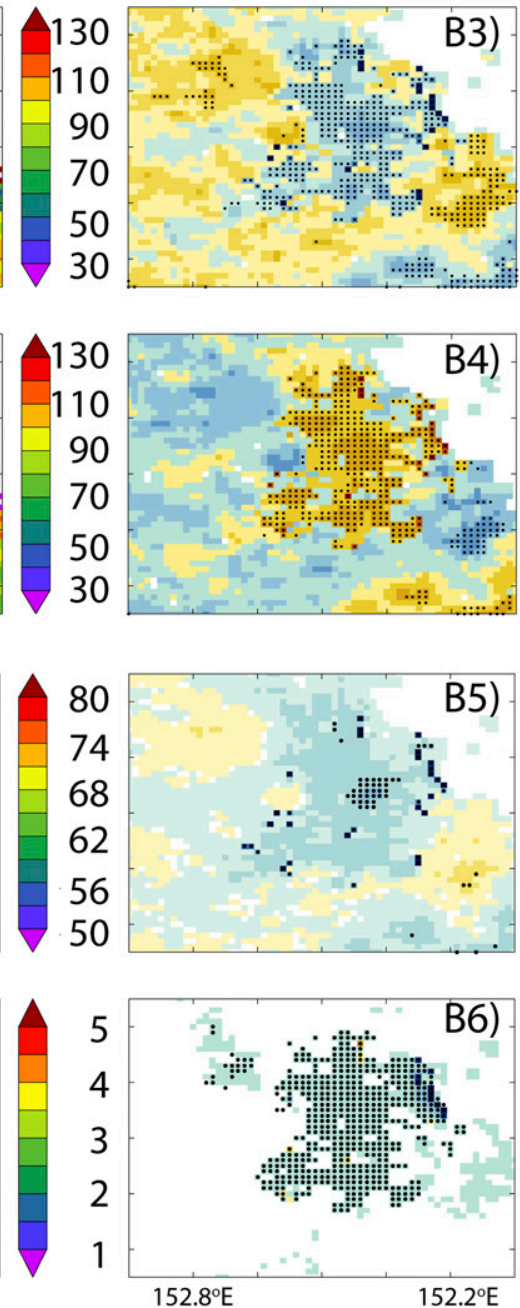
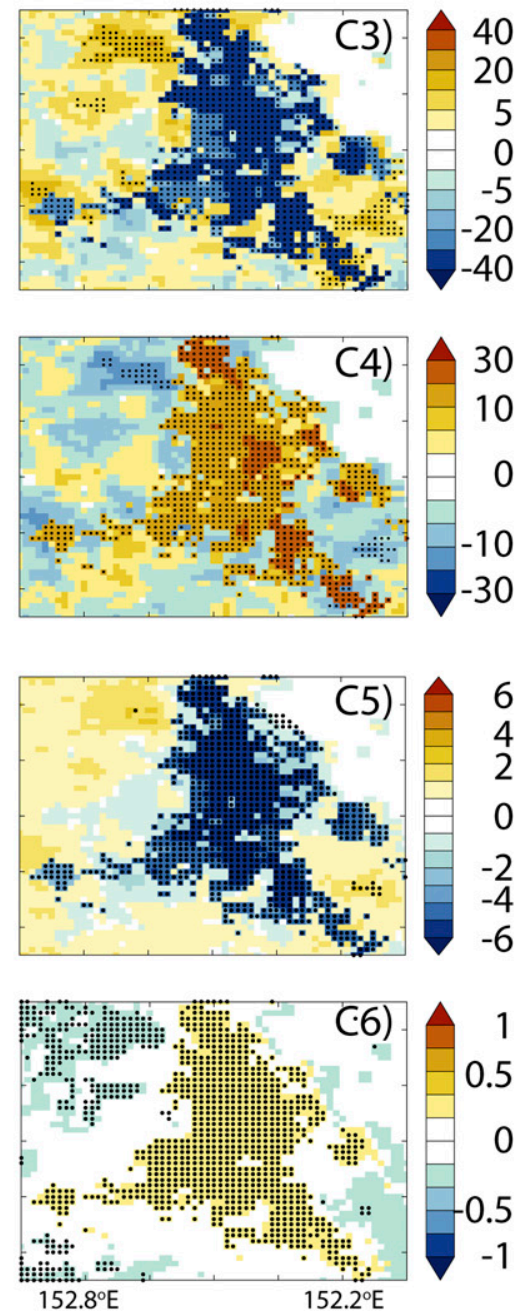

FIG. 5. (a) The value of the variables for the Control, and the difference, calculated as scenario minus Control, between the Control and the scenarios [(b) Medium Density and (c) No Vegetation] for (first row) minimum and (second row) maximum temperature $\left({ }^{\circ} \mathrm{C}\right),($ row 3 ) latent and (row 4) sensible heat flux $\left(\mathrm{W} \mathrm{m}^{-2}\right.$ ), (row 5) relative humidity (\%), and (row 6) 10-m wind speed ( $\mathrm{m} \mathrm{s}^{-1}$ ). Dots indicate changes with confidence level $95 \%$. 


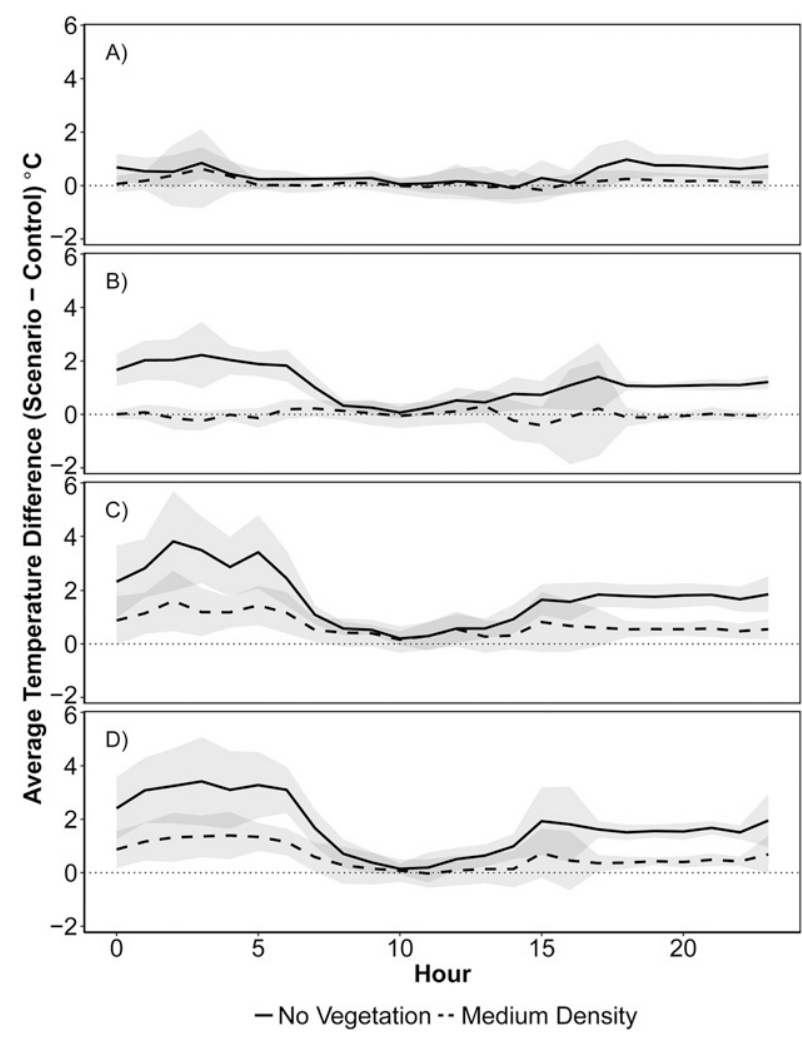

FIG. 6. Average hourly difference in modeled temperature between the urban growth scenarios and Control during two widespread extreme heat events (23-25 Dec 2001 and 19-21 Feb 2004) for (a) Rural, (b) Logan, (c) Archerfield, and (d) Brisbane City weather station locations. The dotted line shows no change between the scenarios and Control. The shaded area shows 1 standard deviation.

events also occurred at Brisbane City. The No Vegetation scenario was the only scenario which experienced extreme heat events that lasted for longer than 5 days. The longest event, which lasted 7 days, occurred at the Brisbane City weather station location and Archerfield in the No Vegetation scenario. This occurred once in the 10 -yr period.

In the 10-yr simulation period, there were only two widespread extreme heat events which affected all four locations: Rural, Archerfield, Logan, and Brisbane City. These events were from 23 to 26 December 2001 and from 20 to 23 February 2004. The February extreme heat event started one day earlier than the Control in the No Vegetation scenario, and finished one day earlier than the Control in the Medium Density scenario. The average hourly temperature difference between the scenarios and the Control during these two events is shown in Fig. 6.

In urban areas during both these events, the mean maximum increase in temperature above the Control for the No Vegetation scenario was between $2.2^{\circ}$ and $3.8^{\circ} \mathrm{C}$, and for the Medium Density scenario, the mean maximum increase was between $0.3^{\circ}$ and $1.6^{\circ} \mathrm{C}$. The average increase in temperature in urban locations during these events for the No Vegetation scenario was between $1.1^{\circ}$ and $1.7^{\circ} \mathrm{C}$, which is higher than the increase in temperature of $0.1^{\circ}-1.0^{\circ} \mathrm{C}$ between No Vegetation and Control scenario found using seasonal averages (Table 5). For the Medium Density scenario, the average increase in temperature above the Control scenario during these two periods was $0.7^{\circ} \mathrm{C}$ at Archerfield and $0.6^{\circ} \mathrm{C}$ at Brisbane City, which is higher than the increase of $0.15^{\circ}-$ $0.20^{\circ} \mathrm{C}$ found using seasonal averages (Table 5). These temperature increases occurred mostly in the evening and early morning and acted to extend the period of high temperatures, rather than increase maximum temperatures.

During the December and February heat events there were short-duration changes in temperature in areas where land cover did not change. At the Rural point, in the afternoon and evenings (1500-0400 LT) the No Vegetation scenario was $0.61^{\circ} \mathrm{C}$ (standard deviation $=$ $0.23^{\circ} \mathrm{C}$ ) warmer than the Control scenario. On average, the temperature in the Medium Density scenario was similar to the Control at Logan, where land cover did not change. However, during the afternoon (1500-1800 LT), the Medium Density scenario was $1^{\circ} \mathrm{C}$ cooler or up to $5^{\circ} \mathrm{C}$ warmer than the Control. During the December 2001 event Logan was warmer $\left(1^{\circ}-5^{\circ} \mathrm{C}\right)$ in the Medium Density scenario than the Control in the afternoon, while during the February event in the afternoons, Logan tended to be cooler $\left(1^{\circ}-1.4^{\circ} \mathrm{C}\right)$ in the Medium Density scenario than in the Control.

\section{e. Hot days and nights}

The average number of hot nights per summer increased significantly above the Control for the No Vegetation scenario (significance level $p<0.05$ ), while there was no significant change in the average number of hot days per summer for either scenario (Fig. 7). The statistical significance of the difference between the average number of hot days and nights per summer between the landcover scenarios and the Control was compared using the Kruskal-Wallis test, as the data were not normally distributed. Hot days were defined as days with temperatures equal to or above the 97.5th percentile of maximum temperature at the Rural point in the Control scenario. This temperature was $42^{\circ} \mathrm{C}$. Similarly, hot nights were defined as temperatures equal to or above the 97.5 th percentile of minimum temperature, which was $23^{\circ} \mathrm{C}$ at the Rural point in the Control scenario.

The average number of hot nights per summer more than doubled in the No Vegetation scenario at Archerfield (17 to 37 nights) and at Brisbane City (23 to 51). For the Medium Density scenario, the increases in the number of hot nights per summer was only significant at the Brisbane City weather station at $p=0.10$. 


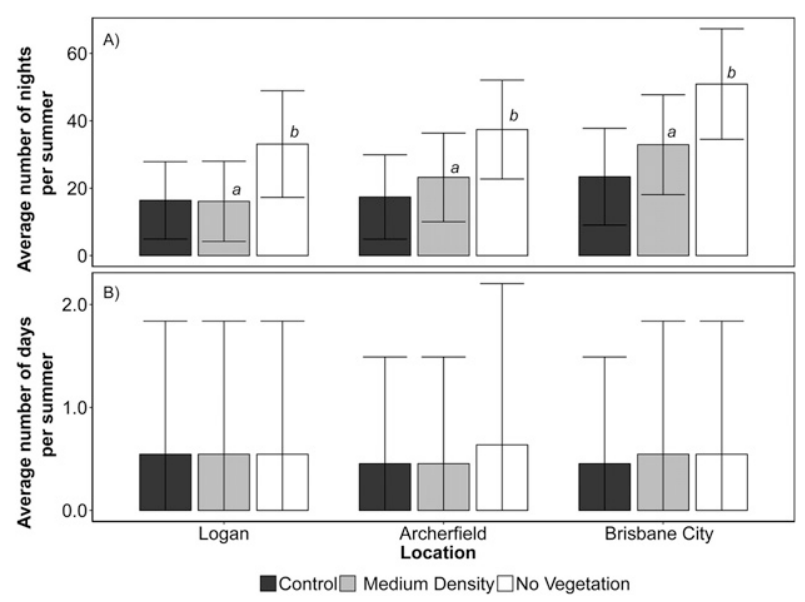

FIG. 7. Average number of hot (a) nights and (b) days per summer (2000-10) for Control and land-cover scenarios, based on model data. The standard deviation is shown with error bars. Hot day defined as a day with the maximum temperature equal to or above the 97.5th percentile of maximum temperature for the Rural point in the Control scenario $\left(42^{\circ} \mathrm{C}\right)$. Hot night defined the same way using minimum temperature $\left(23^{\circ} \mathrm{C}\right)$. Letter "a" indicates that the change in average number of hot nights per summer was not significant at $p<0.05 \%$, and " $\mathrm{b}$ " indicates a significant change in average number of hot nights per summer. There was no significant change in average number of hot days per summer.

\section{f. Urban heat island}

The model UHI (see Fig. 8) was calculated in the same way as the observational UHI, which is the difference in temperature between the Brisbane weather station and the average of Amberley and Brisbane Airport. For the Control scenario, the average model UHI was $0.66^{\circ} \mathrm{C}$, which is warmer than the summer observational UHI (see Fig. 3). Based on the model results, a cool island (urban areas cooler than rural areas) developed in the afternoon for all scenarios except for the No Vegetation scenario. The minimum UHI value was reached around $1500 \mathrm{LT}$ for the Control and was $-0.4^{\circ} \mathrm{C}$. The difference in the UHI effect between the land-cover scenarios and the Control was strongest at night. The maximum intensity UHI was reached in the evening for all scenarios and was $1.8^{\circ} \mathrm{C}$ for the Control, $2.1^{\circ} \mathrm{C}$ for Medium Density, and $2.7^{\circ} \mathrm{C}$ for No Vegetation.

\section{g. Energy budget}

The increase in temperature in the No Vegetation and Medium Density scenarios reflects changes in the latent and sensible heat fluxes. The latent and sensible heat flux increased during the daytime and decreased after sunset (see Fig. 9). For the Rural point (Figs. 9a1 and 9a2), the latent and sensible heat fluxes were similar for all scenarios. For the urban locations, the biggest change in fluxes was for No Vegetation, where latent heat flux dropped below $50 \mathrm{~W} \mathrm{~m}^{-2}$. The sensible heat flux of No Vegetation peaked later in the day compared to the other scenarios and remained higher throughout the evening. The contrast between Control and No Vegetation was stronger for latent heat flux than for the sensible heat flux, suggesting it is the reduction in evapotranspiration driving the temperature increases in this scenario. The biggest changes in latent and sensible heat flux for the Medium Density scenario occurred at the Brisbane City weather station (Figs. 9d1 and 9d2), where the biggest temperature increase also occurred. Latent heat flux was on average $5-10 \mathrm{~W} \mathrm{~m}^{-2}$ lower than the Control at Brisbane City Weather Station. Sensible heat flux for the Medium Density scenario was higher than the Control for Brisbane City weather station during the evening.

The reduction in latent and sensible heat flux for the Medium Density and No Vegetation scenarios was accompanied by an increase in storage during the day and a decrease in the evening in urban areas (see Fig. 10). There is larger change in storage in the No Vegetation scenario than in the Medium Density scenario. There is minimal difference in net radiation between the land-cover scenarios and the Control.

The changes in sensible and latent heat flux for the different scenarios were also reflected in the Bowen ratio, the ratio of sensible to latent heat flux (Fig. 11). The Bowen ratio was similar for all scenarios at the Rural point. For the remaining locations, the seasonal average Bowen ratio for No Vegetation was between 6 and 7 and was consistently higher than for the other scenarios. The main differences between the Medium Density and the Control scenarios occurred at night, when the Bowen ratio for Medium Density was higher than for the Control.

\section{Discussion}

\section{a. Main findings}

In this study, we examined the impact of changes in vegetation cover and urban form (building height, height/ width ratio) on average and extreme temperatures in a subtropical Australian city. We found the average increase in temperature during two extreme heat events was higher than the average summer temperature increase. During these events, temperatures increased in locations outside where land cover changed. This was in contrast to average summer temperatures, which only increased over the areas of land-cover change. Reducing vegetation cover (i.e., shrubs) to zero resulted in larger increases in temperature than increasing building height and reducing the height/width ratio of buildings. Temperature increases were particularly pronounced at night, which led to increases in the average nocturnal heat 


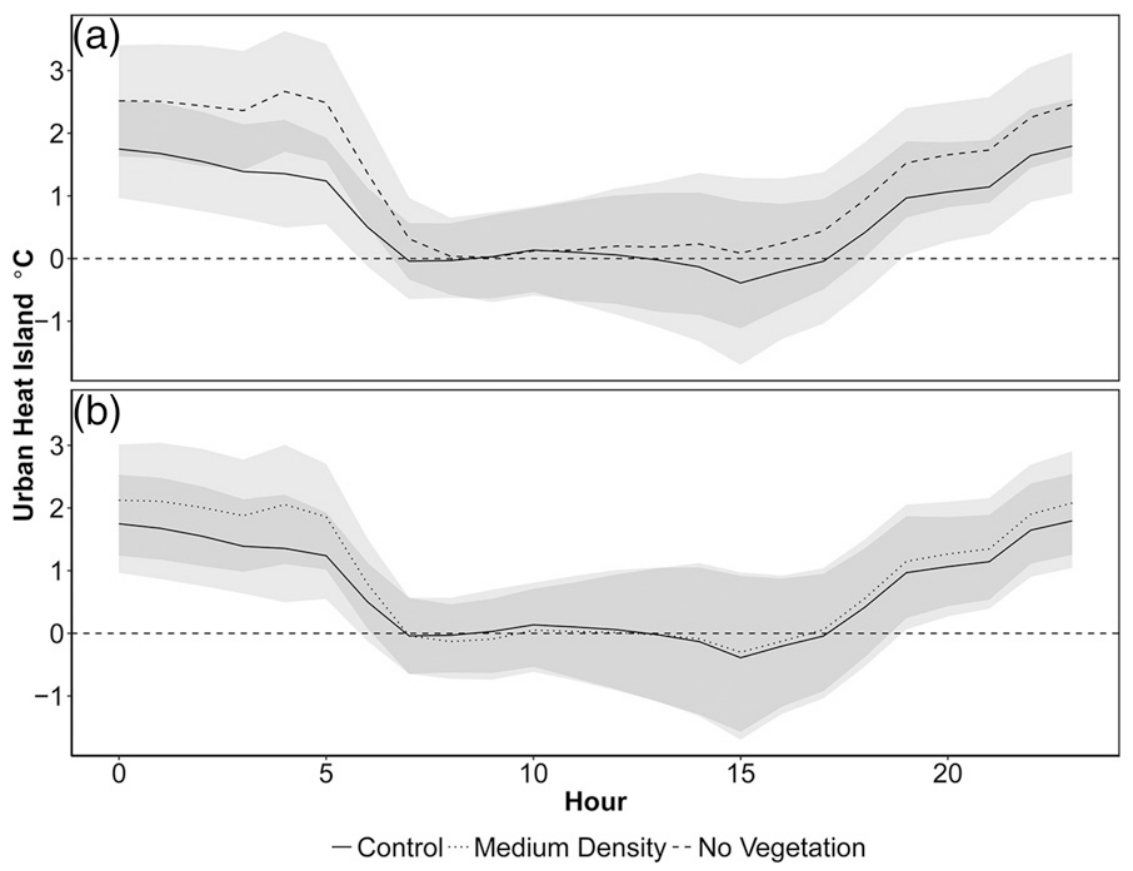

FIG. 8. Average hourly model UHI (Brisbane weather station minus average of Amberley and Brisbane Airport) for all scenarios. (a) The intensity of UHI of the Control scenario and the No Vegetation scenario. (b) The intensity of the UHI of the Control and the Medium Density scenario. The shaded area shows 1 standard deviation.

island of $0.3^{\circ} \mathrm{C}$ for the Medium Density and $0.9^{\circ} \mathrm{C}$ for No Vegetation scenarios.

We found that the processes influencing urban temperatures in temperate cities also apply to subtropical cities. The variables examined (vegetation and building fraction, building height and height/width ratio) had a stronger impact on temperatures during the night than during the day, confirming previous work in temperate cities that the heat island is often strongest at night (Arnfield 2003; Grimmond 2007; Roth 2007; Yow 2007). The average intensity of the observational UHI was $1.4^{\circ} \mathrm{C}$ in winter and $0.4^{\circ} \mathrm{C}$ in summer. This was lower than observed for temperate cities, which can have a mean value of $6{ }^{\circ} \mathrm{C}$ (Wienert and Kuttler 2005; Roth 2007). However, we found the UHI intensity could reach up to $2.8^{\circ} \mathrm{C}$ at night during winter. For Brisbane, the intensity of the UHI was generally higher in winter, the dry season, than in summer, the wet season. Unlike previous work in the subtropics (Arnfield 2003; Roth 2007; Yow 2007), we found both summer-winter seasons and wet-dry could be used to examine seasonal variation in the UHI. Previous work in Brisbane has found there is little seasonal variation in anthropogenic heat release (Chapman et al. 2016). Therefore it is likely that seasonal variation in UHI intensity is due to seasonal variation in weather or thermal admittance (Arnfield 2003). Urban areas generally have higher thermal admittance than rural areas, which is the ability of materials to store and release heat (Yow 2007; Hidalgo et al. 2008). During the wet season the thermal admittance of rural areas increases due to increased moisture content in soils, whereas the thermal admittance of urban areas generally stays the same, which reduces the difference between thermal admittance in urban and rural areas (Arnfield 2003; Roth 2007; Yow 2007). Seasonal variation in the UHI may also be due to seasonal differences in cloud cover, which tends to decrease the UHI. Drier periods are also associated with lower cloud cover (Arnfield 2003; Gedzelman et al. 2003; Yow 2007). Further work, with longerterm seasonal data, would be required to explore the seasonal changes in the UHI in subtropical regions such as Brisbane.

\section{b. The effect of changing land cover on the urban climate}

For both scenarios, the increase in temperature was higher at night than during the day. There was no significant change in the average number of hot days per summer in the No Vegetation and Medium Density scenarios. For the Medium Density scenario, shading from taller buildings may limit daytime warming. At night, the main controls on surface temperature are net longwave admission and thermal admittance, which includes storage capacity and 


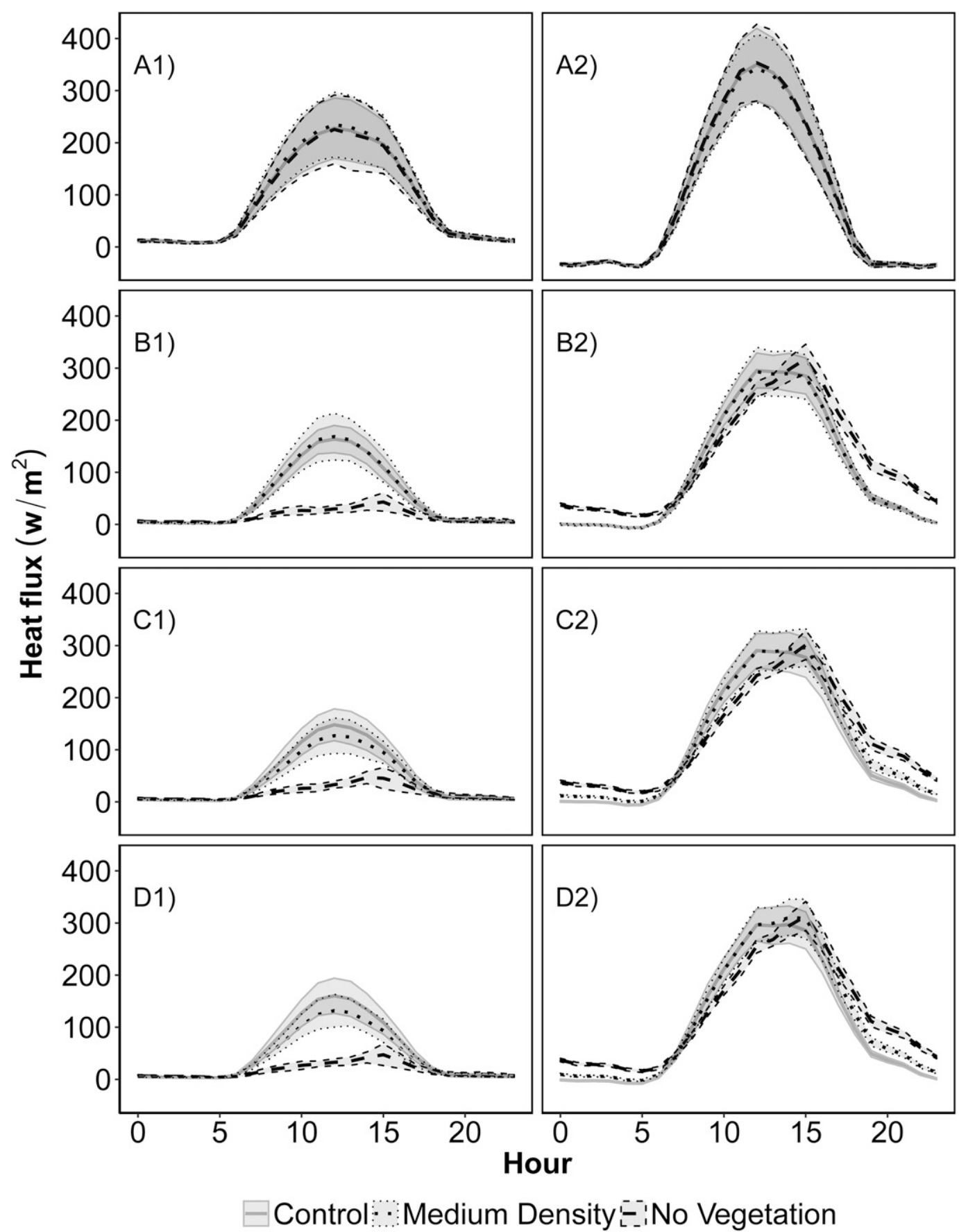

FIG. 9. CCAM seasonal mean hourly variation in (left) latent heat flux and (right) sensible heat flux for summer 2000-10 for all scenarios at the (a) Rural, (b) Logan, (c) Archerfield, and (d) Brisbane City weather station locations. The shaded area shows 1 standard deviation.

conductivity (Oke 1981; Unger 2009; Schrijvers et al. 2015). Therefore, we would expect variables related to storage and longwave emission to have a strong effect on nocturnal temperatures (Oke 1981). Building fraction and vegetation fraction both relate to heat storage as they control the amount of buildings, roads, and vegetation.
Height/width ratio relates to longwave emission as taller buildings, which have a higher height/width ratio, obstruct outgoing radiation (Oke 1981; Unger 2009; Schrijvers et al. 2015). This relationship was also evident in our sensitivity experiments using ATEB, with building fraction, vegetation fraction, and height/width ratio having a stronger 


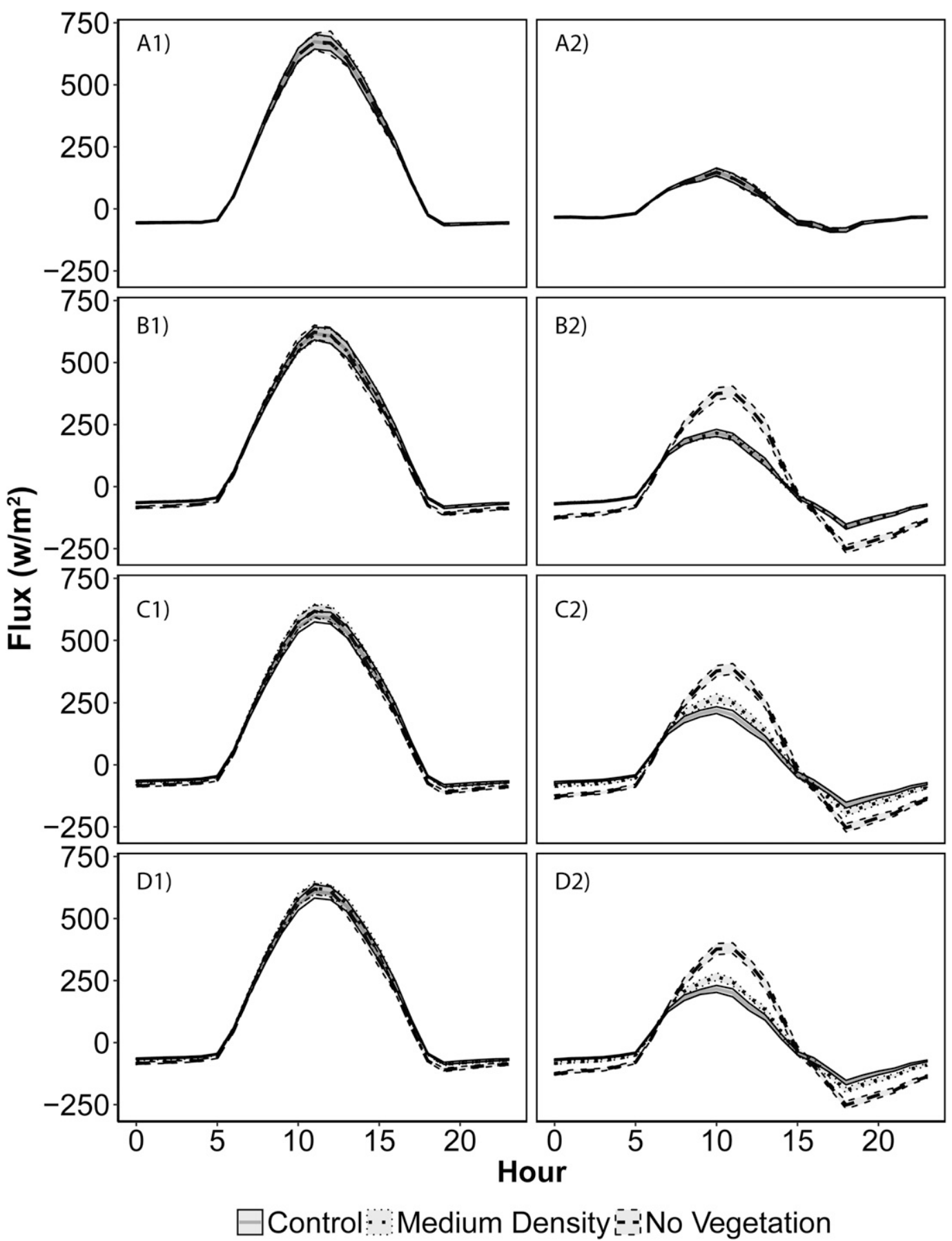

FIG. 10. The seasonal mean and standard deviation in CCAM hourly variation in (left) net radiation and (right) storage flux for summer 2000-10 for all scenarios at the (a) Rural, (b) Logan, (c) Archerfield, and (d) Brisbane City weather station locations. The shaded area shows 1 standard deviation.

effect on temperatures at night than during the day. A stronger change in temperature during the night than the day may also be due to a shallower nocturnal boundary layer and reduced effective heat capacity (Davy and Esau 2016).
Vegetation cover had a larger impact on temperatures than variables related to urban geometry, such as building height and height/width ratio. Temperatures increased by $0.13^{\circ}-1.3^{\circ} \mathrm{C}$ more in the No Vegetation scenario than the Medium Density scenario. The sensitivity experiments in 


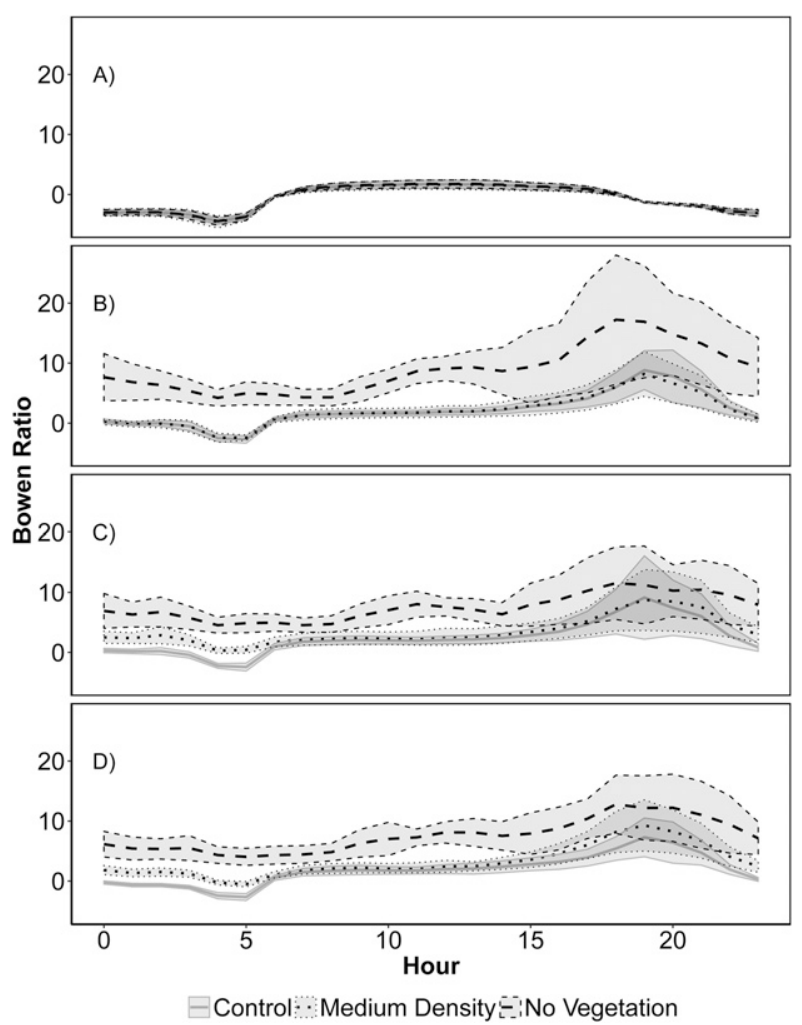

FIG. 11. The seasonal average hourly variation in Bowen ratio (sensible heat flux/latent heat flux) for summer 2000-10 for each scenario at the (a) Rural, (b) Logan, (c) Archerfield, and (d) Brisbane City weather stations, based on model data. One standard deviation is represented by the shaded area.

appendix A also show this pattern. ATEB was run offline to explore the changes in temperature from changing the variables altered in the Medium Density scenario in isolation. These offline runs showed the $11 \%$ reduction in green space in the Medium Density scenario could, by itself, lead to warming of $0.51^{\circ} \mathrm{C}$ during the day and $0.89^{\circ} \mathrm{C}$ at night, while the increase in height/width ratio of 0.2 alone resulted in a cooling during the day of $0.13^{\circ} \mathrm{C}$ and a warming at night of $0.29^{\circ} \mathrm{C}$. While the online model will behave differently than the offline urban canopy model, these results do suggest reducing urban vegetation cover has a more consistent warming effect, increasing temperatures at night and during the day, than building height and height/width ratio. Vegetation reduces temperatures by shading and evapotranspiration (Oke 1982; Loughner et al. 2012; Gunawardena et al. 2017). A reduction in vegetation means more energy is partitioned into sensible rather than latent heat (Oke 1982; Hidalgo et al. 2008; Gunawardena et al. 2017). This is supported by our results, which showed a reduction in evapotranspiration under No Vegetation was the main process driving temperature increases (Fig. 9). Previous work has shown that urban form is an important contributor to the magnitude of the urban heat island (Arnfield 2003; Adachi et al. 2014; Schrijvers et al. 2015; Chapman et al. 2017). In our study, this is represented by the impact of the Medium Density scenario on urban temperatures. However, on the basis of the modeling results for our land-cover scenarios, and the offline studies, we believe that the amount of vegetation cover may be a more important factor than urban geometry in controlling UHI intensity in subtropical cities.

\section{c. Extreme heat events}

The duration of extreme heat events increased in both scenarios. The average increase in temperature during extreme heat events was higher than during seasonal average conditions. In the No Vegetation scenario, there were more frequent and longer duration extreme heat events than in the Control or the Medium Density scenario. The Medium Density scenario did not have more frequent extreme heat events than the Control, although the Brisbane City location extreme heat events lasted longer.

During two widespread extreme heat events, the increases in temperature in the urban growth scenarios were higher than the average change in seasonal temperatures. The temperature also changed at locations where the land cover did not change. There are a number of factors that could explain these results. One possible explanation is changes in wind speed and direction. Wind may have carried warmer urban air over rural areas, and urban areas where land cover did not change, temporarily increasing temperature above the Control. In the early morning (0500 LT onward) and some afternoons of the February and December extreme heat events, the wind blew across the city and over the Rural point, bringing the warmer urban air with it (see appendix B for a time series of wind at the Rural point during the December extreme heat event). On average, the Medium Density scenario had slightly lower wind speeds than the Control. During the December event, wind speeds in the afternoon were low in the Control but were even lower in the Medium Density scenario, which may have led to increases in temperature in Logan, an urban area where land cover did not change, as warmer urban temperatures have been associated with low wind speeds (Arnfield 2003). During the February event, the wind speeds dropped in the afternoon, but not for as long as in December. This partially corresponds to the theory suggested by Li and Bou-Zeid (2013) that a drop in wind speed during heat waves intensifies the UHI. The lower wind speeds in the Medium Density scenario may have led to a more intense UHI than in the Control. However, based on the number of events examined here, it is difficult to show conclusively the reasons for these 
short-term changes in temperature. Further research is required to examine more extreme heat events and more processes that could be responsible for an increase in urban temperatures during extreme heat events, such as evaporation and soil moisture. Further research is also required to understand the processes that could be responsible for increases in temperature in areas where land cover did not change, such as the weather conditions and how frequently these conditions occur.

\section{d. Approach and limitations}

This study used a high-resolution climate model to investigate the impact of urban growth on temperatures in a subtropical city. The use of a $1-\mathrm{km}$ resolution allowed us to include multiple types of urban land cover in the model, which has been a limitation in previous work (Chapman et al. 2017). We also examined multiple scenarios, enabling us to assess the impact of an extreme No Vegetation scenario to isolate the impact of vegetation and a more realistic Medium Density scenario. The limitations of this study are related primarily to the time frame examined and the weather observation data. We examined the summer UHI due to resource constraints and were unable to examine how urban growth would impact the UHI throughout the year. While the intensity of the UHI is greatest during winter and may be useful to examine, the summer UHI will have the greatest impact on heat stress of urban residents. The observational UHI was calculated using weather station data; however, for the time period examined (2000-10), the most rural stations were Amberley and Brisbane Airport, which are more properly classified as urban fringe (Trewin 2013). Further, Brisbane Airport is located close to the coast and Amberley has a higher elevation than the city. While a more rural station would have been ideal, none were available. The stations used were able to demonstrate the difference in temperature between the city center and less urbanized areas.

Further limitations include the urban parameters used in the urban climate model, which were based on data from temperate Melbourne rather than subtropical Brisbane because these data were the best available for an Australian city. The model validation confirmed a warm bias when simulating Brisbane and is most noticeable in the simulated daily maximum temperatures. We have investigated various potential reasons for the high maximum temperature, but have not clearly identified the cause. The land surface albedo predicted by the CSIRO Atmosphere Biosphere Land Exchange (CABLE) and ATEB appears consistent with the observed values in the region. Most of the weather station elevations are within $3 \mathrm{~m}$ of the average elevation used by the model, with the worst case for Brisbane airport being $7 \mathrm{~m}$ higher than the model elevation. It is possible that the bias is related to the downscaling of the CCAM $100-\mathrm{km}$ resolution simulation forced by ACCESS-corrected sea surface temperatures. However, ACCESS sea surface temperatures are necessary to make a prediction of the future Brisbane climate under a plausible global warming scenario, and the corrected sea surface temperatures generally improve the simulated present-day climate. Nevertheless, in future work we will consider sea surface temperatures from other GCMs to determine their impact on the simulated Brisbane climate. Future work will also examine the implications for urban temperatures outside of summer and improve the input data available for the model parameters.

\section{e. Implications for urban planning}

The Medium Density scenario had relatively minor increases in density; however, this was enough for nocturnal temperatures to increase by $0.7^{\circ} \mathrm{C}$ in the inner city. During the two extreme heat events, the mean maximum temperature increase was $1.4^{\circ} \mathrm{C}$ in the inner city. The No Vegetation scenario saw higher increases in temperature, highlighting the importance of urban green space in managing urban temperatures. The Medium Density scenario saw increases in building height from 6 to $8 \mathrm{~m}$ and a reduction in vegetation of $11 \%$. The high temperature changes seen with relatively minor changes to urban form indicate the importance of mitigating the UHI to reduce the risk of heat stress. Increase in density in the inner city may be higher than that modeled here, as high-density residential can go up to 15 stories (Brisbane City Council 2014). Brisbane is therefore likely to experience more pronounced changes to land cover than modeled here, and hence higher increases in temperature. The increase in temperature in the simplified Medium Density scenario and the high increases during hot summer days highlight the importance of careful urban planning and efforts to incorporate heat mitigation, such as urban greening, to reduce the risk of heat-related illness and death ( $\mathrm{Li}$ et al. 2015).

Urban residents are already at higher risk of heat stress due to the UHI (Clarke 1972; Luber and McGeehin 2008; Basara et al. 2010; Li and Bou-Zeid 2013). This risk may be intensified during heat waves, due to synergistic interactions between heat waves and the drivers of the UHI (Li and Bou-Zeid 2013). Careful urban planning is required to mitigate this risk and reduce adverse health consequences (Grimmond 2007; Li and Bou-Zeid 2013). Mitigation can occur at the building scale, including material choice for new developments, green roofs, and retrofitting existing buildings, or at the 
neighborhood scale, with spacing of buildings, planting of street trees, and allocation of green space (Grimmond 2007; Li et al. 2015; Ramakrishnan et al. 2016; Sun et al. 2016). Building materials, which affect thermal admittance, and the height and spacing of buildings affect the heat island (Grimmond 2007). However, our study shows vegetation cover was the most important factor. Lack of evapotranspiration from grass and trees is a key driver of the heat island, particularly during heat waves ( $\mathrm{Li}$ et al. 2015). The allocation of green space needs to be planned carefully. The type of vegetation and its placement are important factors, as they will affect the timing and amount of cooling, as well as the amount of irrigation required during dry periods (Coutts et al. 2016; Gunawardena et al. 2017; Zhou et al. 2017).

\section{Conclusions}

We examined the impact of land-cover change on the urban heat island in Brisbane, a subtropical city, during summer. We found that a reduction in vegetation cover had the biggest impact on urban temperatures. During a period of hot days, the increase in temperature in the urban growth scenarios was higher than for average temperatures, with a mean maximum increase of $3.8^{\circ} \mathrm{C}$ in the No Vegetation scenario. The large temperature increases seen with relatively minor changes to urban form in the Medium Density scenario, particularly during a period of hot days, show how important careful urban planning is to mitigate the UHI and protect the health of urban residents. Vegetation restoration is a key mitigation strategy. However, the placement and type of vegetation needs to be carefully considered to ensure the maximum cooling potential during heat waves. In subtropical cities, temperature increases associated with the UHI could have a negative impact on the health of residents, especially the elderly and economically disadvantaged, and lead to increases in heat-related illness and death. Considering the temperature impacts of urban land-cover change and incorporating mitigation measures into urban planning should be priorities in subtropical cities.

Acknowledgments. This research was undertaken with the assistance of resources and services from the National Computational Infrastructure (NCI), which is supported by the Australian Government. We thank the Brisbane City Council for providing Brisbane zoning data. Data were also provided by Remote Sensing Research Centre, School of Earth and Environmental Sciences, The University of Queensland, derived from Airborne Lidar data provided by the
TABLE A1. Sensitivity experiments for the ATEB model, the urban canopy model used in CCAM.

\begin{tabular}{ccc}
\hline \hline Expt & \multicolumn{1}{c}{ Variables } & \multicolumn{1}{c}{ Description } \\
\hline 1 & $\begin{array}{c}\text { Building and vegetation } \\
\text { fraction }\end{array}$ & $\begin{array}{c}\text { Change both building fraction } \\
\text { and vegetation fraction to see } \\
\text { the impact on temperatures } \\
\text { Change the height/width ratio } \\
\text { of buildings } \\
\text { Change the vegetation } \\
\text { roughness length, which is } \\
\text { related to the height of } \\
\text { vegetation }\end{array}$ \\
\hline
\end{tabular}

Queensland Government. Author SC was supported by an Australian Postgraduate Award. This project was supported by Australian Research Council Discovery Project DP160102107.

\section{APPENDIX A}

\section{Sensitivity Experiments}

The urban canopy model ATEB was run for one year in Brisbane to assess how temperatures responded to variations in building fraction, height/width ratio, vegetation fraction, and vegetation roughness length (VRL), as shown in Table A1. Vegetation roughness length is related to the height and spacing of roughness elements, such as trees, shrubs, and buildings, and can be approximated as 0.1 multiplied by the height of the roughness element (Oke 2002).

Vegetation was more effective at reducing temperatures at night than during the day (Fig. A1). During the

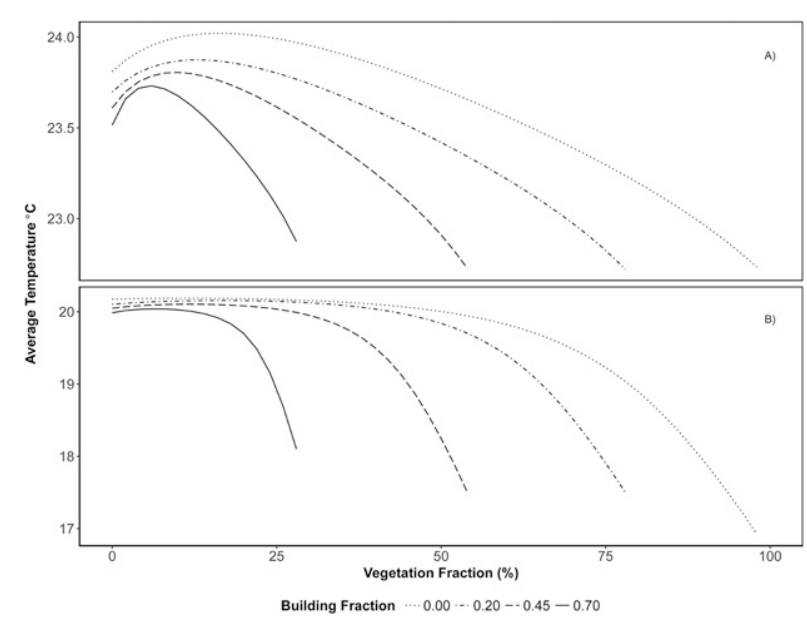

FIG. A1. Variation in average temperature in ATEB as building and vegetation fraction vary for (a) day (0600-1700 LT) and (b) night (1800-0500 LT). 


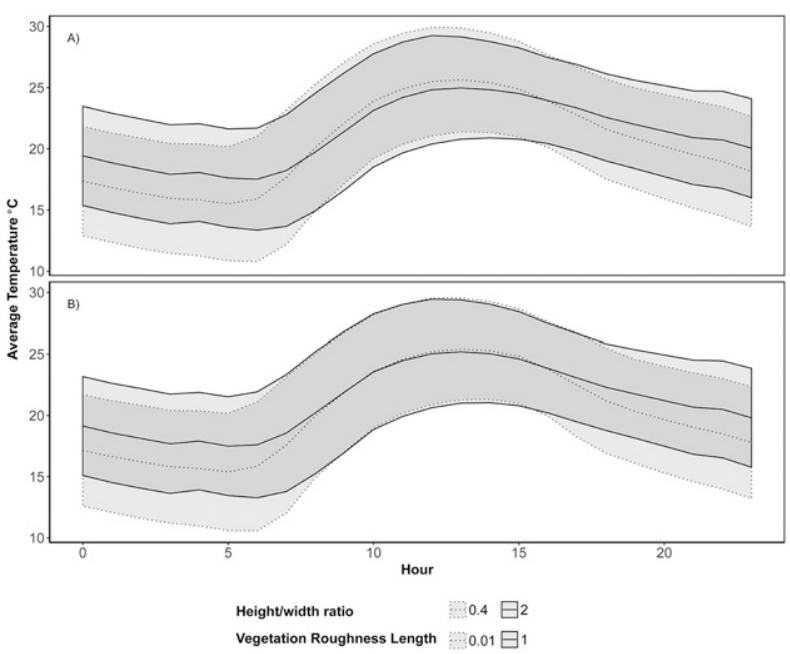

FIG. A2. ATEB hourly variation in average temperature in 2000 for (a) height/width ratio and (b) vegetation roughness length. Height/width ratio of $0.4=$ urban-low and $2=$ urban-high. The shaded area shows 1 standard deviation.

day, as vegetation fraction increased from $0 \%$ to $100 \%$, the temperature decreased by $1.08^{\circ} \mathrm{C}$. At night, the temperature difference between $0 \%$ and $100 \%$ vegetation was $3.25^{\circ} \mathrm{C}$.

Roads had a strong influence on temperature. In ATEB, the difference between building and vegetated fraction is assigned to roads. As vegetation stays the same and building fraction increases, buildings are replacing roads, which have a lower albedo than building roofs and walls. The lower temperatures associated with higher building fractions reflects the replacement of roads with buildings.

VRL also affected temperature, with a larger roughness length associated with lower temperatures during the day and higher temperatures at night (Fig. A2b). Between 0400 and $0500 \mathrm{LT}$, there was a $2.1^{\circ}-2.2^{\circ} \mathrm{C}$ temperature difference between the VRL 1 and VRL 0.01 scenarios. This decreased throughout the day, and the VRL 1 scenario became cooler than the VRL 0.01 scenario after 1000 LT. The temperature difference reversed again at $1600 \mathrm{LT}$. The larger temperature changes at night may also be related to a shallower boundary layer at night and a lower effective heat capacity, which can magnify the effect of perturbations on temperature (Davy and Esau 2016).

During the day, a higher height/width $(\mathrm{H} / \mathrm{W})$ ratio was associated with lower temperatures, whereas during the night it was associated with higher temperatures (Fig. A2a). At midnight, the scenario with a $\mathrm{H} / \mathrm{W}$ ratio of 2, which corresponds to high density, was $2.1^{\circ} \mathrm{C}$ warmer than the H/W 0.4 scenario, which corresponds to low density. During the day, the H/W 2 scenario was $0.7^{\circ} \mathrm{C}$ cooler than the $\mathrm{H} / \mathrm{W} 0.4$ scenario. A higher $\mathrm{H} / \mathrm{W}$ ratio is associated with taller buildings, narrow canyons, and a lower sky-view factor. During the day, this provides shading and reduces temperatures, whereas at night it reduces outgoing radiation and cooling (Oke 1982; Sakakibara 1996; Loughner et al. 2012).

ATEB was also used to explore the impact of changing the parameters altered in the Medium Density scenario in isolation. Table A2 shows the change in temperature from changing building height, $\mathrm{H} / \mathrm{W}$ ratio, and vegetated fraction in isolation, relative to the temperature obtained from using the urban-low parameters. A change in building height of $2 \mathrm{~m}$, the same change in building height used in the Medium Density scenario, has a minimal effect on temperatures. Reducing vegetation increases temperatures at night and during the day, while increasing $\mathrm{H} / \mathrm{W}$ ratio decreases temperatures slightly during the day and increases temperature during the evening. These results show that of the parameters changed in the Medium Density scenario, the reduction in vegetation likely led to the most consistent warming effect.

\section{APPENDIX B}

\section{Wind Speed and Direction during Heat-Wave Events}

During the extreme heat events, the temperature changed even at locations where land cover did not change. This may be partially due to wind speed and direction. Figure B1 shows the wind speed and temperature for the Control and Medium Density scenarios during 24 December at Logan, a low-density urban area where land cover did not change. During the heat wave, temperature was higher in the afternoon in the Medium

TABLE A2. Change in temperature $\left({ }^{\circ} \mathrm{C}\right)$ with change in single parameters, as compared with the urban-low parameter values. All other parameters are the same as for the urban-low category.

\begin{tabular}{ccccc}
\hline \hline Time & $\begin{array}{c}\text { Building height } \\
\text { (from 6 to 8 })\end{array}$ & $\begin{array}{c}\text { Height/width ratio } \\
\text { (from 0.4 to 0.6) }\end{array}$ & $\begin{array}{c}\text { Green-space fraction } \\
\text { (from 45\% to 34\%) }\end{array}$ & $\begin{array}{c}\text { Green-space fraction } \\
\text { (from 45\% to 0\%) }\end{array}$ \\
\hline 0600-1800 LT & 0.02 & -0.13 & 0.29 & 0.51 \\
1830-0530 LT & -0.02 & 0.28 & 0.68 & 0.87 \\
\hline
\end{tabular}




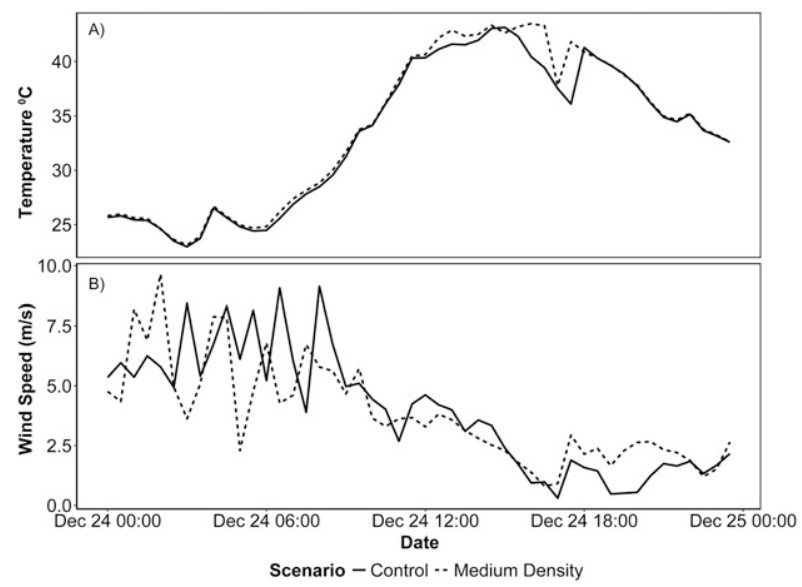

FIG. B1. (a) CCAM half-hourly temperature $\left({ }^{\circ} \mathrm{C}\right)$ and (b) CCAM wind speed $\left(\mathrm{m} \mathrm{s}^{-1}\right)$ at Logan for the Control and Medium Density scenarios during one day of the December 2001 heatwave event.

Density scenario than in the Control. During this time, wind speed dropped, more so in the Medium Density scenario than in the Control.

During both heat events, temperatures were also warmer at the Rural location in the No Vegetation scenario than in Control, even though land cover did not change there. This may have been partially due to wind blowing across the city and over the urban area. Figure B2 shows the variation in wind speed, direction, and temperature for 25 and 26 December for the Control and No Vegetation scenario. The remainder of the wind speed and direction data is available on request to the authors.

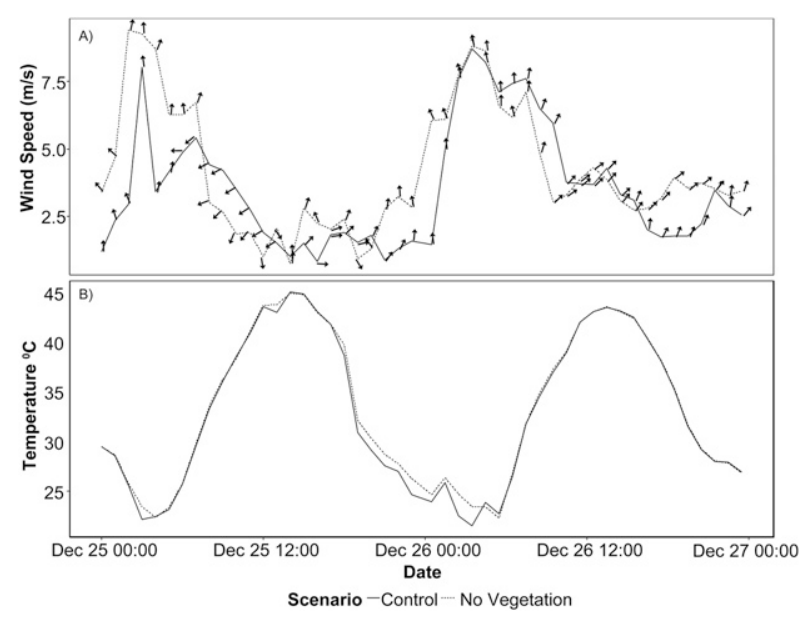

FIG. B2. (a) CCAM half-hourly wind speed $\left(\mathrm{m} \mathrm{s}^{-1}\right)$ and direction and (b) CCAM temperature $\left({ }^{\circ} \mathrm{C}\right)$ at the Rural location during 25 and 26 Dec 2001. Arrows show the direction to which the wind is blowing. The Rural point is located southwest of the urban area.

\section{REFERENCES}

Adachi, S. A., F. Kimura, H. Kusaka, M. G. Duda, Y. Yamagata, H. Seya, K. Nakamichi, and T. Aoyagi, 2014: Moderation of summertime heat island phenomena via modification of the urban form in the Tokyo metropolitan area. J. Appl. Meteor. Climatol., 53, 1886-1900, https://doi.org/10.1175/JAMC-D-13-0194.1.

Arnfield, A. J., 2003: Two decades of urban climate research: A review of turbulence, exchanges of energy and water, and the urban heat island. Int. J. Climatol., 23, 1-26, https://doi.org/ 10.1002/joc.859.

Australian Bureau of Statistics, 2013: Population projections, Australia, 2012 (base) to 2101. Australian Bureau of Statistics Doc., 56 pp., http:/www.abs.gov.au/AUSSTATS/abs@.nsf/DetailsPage/ 3222.02012\%20(base)\%20to\%202101? OpenDocument.

Basara, J. B., H. G. Basara, B. G. Illston, and K. C. Crawford, 2010: The impact of the urban heat island during an intense heat wave in Oklahoma City. Adv. Meteor., 2010, 230365, http:// dx.doi.org/10.1155/2010/230365.

Bi, D. H., and Coauthors, 2013: The ACCESS coupled model: Description, control climate and evaluation. Aust. Meteor. Oceanogr. J., 63, 41-64, https://doi.org/10.22499/2.6301.004.

Brisbane City Council, 2014: Brisbane City Plan 2014. Accessed 3 August 2018, https://www.brisbane.qld.gov.au/planning-building/ planning-guidelines-tools/brisbane-city-plan-2014.

Broitman, D., and E. Koomen, 2015: Residential density change: Densification and urban expansion. Comput. Environ. Urban Syst., 54, 32-46, https://doi.org/10.1016/j.compenvurbsys.2015.05.006.

Bureau of Meteorology, 2017: Summary statistics Brisbane. Commonwealth of Australia, accessed 15 February 2016, http:// www.bom.gov.au/climate/averages/tables/cw_040223.shtml.

Chan, E. H. W., and E. H. K. Yung, 2004: Is the development control legal framework conducive to a sustainable dense urban development in Hong Kong? Habitat Int., 28, 409-426, https://doi.org/10.1016/S0197-3975(03)00040-7.

Chang, C.-R., M.-H. Li, and S.-D. Chang, 2007: A preliminary study on the local cool-island intensity of Taipei city parks. Landscape Urban Plann., 80, 386-395, https://doi.org/10.1016/ j.landurbplan.2006.09.005.

Chapman, S., J. E. M. Watson, and C. A. McAlpine, 2016: Large seasonal and diurnal anthropogenic heat flux across four Australian cities. J. South. Hemisphere Earth Syst. Sci., 66, 342-360, https://doi.org/10.22499/3.6003.00006.

,-- A. Salazar, M. Thatcher, and C. A. McAlpine, 2017: The impact of urbanization and climate change on urban temperatures: A systematic review. Landscape Ecol., 32, 19211935, https://doi.org/10.1007/s10980-017-0561-4.

Chen, D., X. Wang, M. Thatcher, G. Barnett, A. Kachenko, and R. Prince, 2014: Urban vegetation for reducing heat related mortality. Environ. Pollut., 192, 275-284, https://doi.org/10.1016/ j.envpol.2014.05.002.

- M. Thatcher, X. Wang, G. Barnett, A. Kachenko, and R. Prince, 2015: Summer cooling potential of urban vegetation-A modeling study for Melbourne, Australia. AIMS Environ. Sci., 2, 648667, https://doi.org/10.3934/environsci.2015.3.648.

Chouinard, C., M. Béland, and N. McFarlane, 1986: A simple gravity wave drag parametrization for use in medium-range weather forecast models. Atmos.-Ocean, 24, 91-110, https:// doi.org/10.1080/07055900.1986.9649242.

City of Melbourne, 2016: Future Melbourne 2026. Accessed 3 August 2018, https://www.melbourne.vic.gov.au/about-melbourne/ future-melbourne/future-melbourne-2026-plan/Pages/futuremelbourne-2026-plan.aspx. 
Clarke, J. F., 1972: Some effects of the urban structure on heat mortality. Environ. Res., 5, 93-104, https://doi.org/10.1016/ 0013-9351(72)90023-0.

Coutts, A. M., J. Beringer, and N. J. Tapper, 2007: Impact of increasing urban density on local climate: Spatial and temporal variations in the surface energy balance in Melbourne, Australia. J. Appl. Meteor. Climatol., 46, 477-480, 482-493, https:// doi.org/10.1175/JAM2462.1.

,-- , and — 2008: Investigating the climatic impact of urban planning strategies through the use of regional climate modelling: A case study for Melbourne, Australia. Int. J. Climatol. 28, 1943-1957, https://doi.org/10.1002/joc.1680.

_ E. C. White, N. J. Tapper, J. Beringer, and S. J. Livesley, 2016: Temperature and human thermal comfort effects of street trees across three contrasting street canyon environments. Theor. Appl. Climatol., 124, 55-68, https://doi.org/10.1007/s00704-015-1409-y.

Davy, R., and I. Esau, 2016: Differences in the efficacy of climate forcings explained by variations in atmospheric boundary layer depth. Nat. Commun., 7, 11 690, https://doi.org/10.1038/ ncomms11690.

Gedzelman, S. D., S. Austin, R. Cermak, N. Stefano, S. Partridge, S. Quesenberry, and D. A. Robinson, 2003: Mesoscale aspects of the urban heat island around New York City. Theor. Appl. Climatol., 75, 29-42, https://doi.org/10.1007/s00704-002-0724-2.

Global Land Cover Facility, 2018: MODIS land cover. University of Maryland, http://glcf.umd.edu/data/lc/.

Grimmond, C. S. B., 2007: Urbanization and global environmental change: Local effects of urban warming. Geogr. J., 173, 83-88, https://doi.org/10.1111/j.1475-4959.2007.232_3.x.

—_, and T. R. Oke, 1991: An evapotranspiration-interception model for urban areas. Water Resour. Res., 27, 1739-1755, https:// doi.org/10.1029/91WR00557.

Gunawardena, K. R., M. J. Wells, and T. Kershaw, 2017: Utilising green and bluespace to mitigate urban heat island intensity. Sci. Total Environ., 584-585, 1040-1055, https://doi.org/10.1016/ j.scitotenv.2017.01.158.

Hajat, S., M. O'Connor, and T. Kosatsky, 2010: Health effects of hot weather: from awareness of risk factors to effective health protection. Lancet, 375, 856-863, https://doi.org/10.1016/ S0140-6736(09)61711-6.

Heisler, G. M., 1977: Trees modify metropolitan climate and noise. J. Arboric., 3, 201-207.

Hidalgo, J., V. Masson, A. Baklanov, G. Pigeon, and L. Gimeno, 2008: Advances in urban climate modeling. Ann. N. Y. Acad. Sci., 1146, 354-374, https://doi.org/10.1196/annals.1446.015.

Hoffmann, P., J. J. Katzfey, J. L. McGregor, and M. Thatcher, 2016: Bias and variance correction of sea surface temperatures used for dynamical downscaling. J. Geophys. Res. Atmos., 121, 12 877-12 890, https://doi.org/10.1002/2016JD025383.

Holtslag, A. A. M., and B. A. Boville, 1993: Local versus nonlocal boundary-layer diffusion in a global climate model. J. Climate, 6, 1825-1842, https://doi.org/10.1175/1520-0442(1993)006<1825: LVNBLD $>2.0 . C O ; 2$.

Hyatt, O. M., B. Lemke, and T. Kjellstrom, 2010: Regional maps of occupational heat exposure: Past, present, and potential future. Global Health Action, 3, 5715, https://doi.org/10.3402/ gha.v3i0.5715.

Karam, H. A., A. J. Pereira Filho, V. Masson, J. Noilhan, and E. P. Marques Filho, 2010: Formulation of a tropical town energy budget (t-TEB) scheme. Theor. Appl. Climatol., 101, 109-120, https://doi.org/10.1007/s00704-009-0206-x.

Kowalczyk, E., Y. P. Wang, R. M. Law, H. L. Davies, J. L. McGregor, and G. Abramowitz, 2006: The CSIRO Atmo- sphere Biosphere Land Exchange (CABLE) model for use in climate models and as an offline model. CSIRO Marine and Atmospheric Research Paper 013, 42 pp.

Li, D., and E. Bou-Zeid, 2013: Synergistic interactions between urban heat islands and heat waves: The impact in cities is larger than the sum of its parts. J. Appl. Meteor. Climatol., 52, 2051-2064, https://doi.org/10.1175/JAMC-D-13-02.1.

—, T. Sun, M. Liu, L. Yang, L. Wang, and Z. Gao, 2015: Contrasting responses of urban and rural surface energy budgets to heat waves explain synergies between urban heat islands and heat waves. Environ. Res. Lett., 10, 054009, https://doi.org/ 10.1088/1748-9326/10/5/054009.

Lin, Y.-L., R. D. Farley, and H. D. Orville, 1983: Bulk parameterization of the snow field in a cloud model. J. Climate Appl. Meteor., 22, 1065-1092, https://doi.org/10.1175/1520-0450(1983) 022<1065:BPOTSF $>2.0 . \mathrm{CO} ; 2$.

Loughner, C. P., D. J. Allen, D. Zhang, K. E. Pickering, R. R. Dickerson, and L. Landry, 2012: Roles of urban tree canopy and buildings in urban heat island effects: Parameterization and preliminary results. J. Appl. Meteor. Climatol., 51, 17751793, https://doi.org/10.1175/JAMC-D-11-0228.1.

Luber, G., and M. McGeehin, 2008: Climate change and extreme heat events. Amer. J. Prev. Med., 35, 429-435, https://doi.org/ 10.1016/j.amepre.2008.08.021.

Luhar, A. K., M. Thatcher, and P. J. Hurley, 2014: Evaluating a building-averaged urban surface scheme in an operational mesoscale model for flow and dispersion. Atmos. Environ., 88, 47-58, https://doi.org/10.1016/j.atmosenv.2014.01.059.

Masson, V., 2000: A physically-based scheme for the urban energy budget in atmospheric models. Bound.-Layer Meteor., 94, 357-397, https://doi.org/10.1023/A:1002463829265.

McGregor, J. L. 2003: A new convection scheme using a simple closure. Current Issues in the Parameterization of Convection: Extended Abstracts of Presentations at the Fifteenth Annual BMRC Modelling Workshop, P. J. Meighen and A. J. Hollis, Eds., Bureau of Meteorology Research Centre, 33-36.

- and M. R. Dix, 2001: The CSIRO conformal-cubic atmospheric GCM. IUTAM Symposium on Advances in Mathematical Modelling of Atmosphere and Ocean Dynamics, P. F. Hodnett, Ed., Springer, 197-202.

— and - 2008: An updated description of the conformalcubic atmospheric model. High Resolution Numerical Modelling of the Atmosphere and Ocean, K. Hamilton and W. Ohfuchi, Eds., Springer, 51-75.

, H. B. Gordon, I. G. Watterson, M. R. Dix, and L. D. Rotstayn, 1993: The CSIRO 9-level atmospheric general circulation model. CSIRO Tech. Paper 26, 93 pp., http://www. cmar.csiro.au/e-print/open/mcgregor_1993a.pdf.

NSW Department of Planning and Environment, 2014: A plan for growing Sydney. NSW Government Rep., https://gsc-public-1. s3.amazonaws.com/s3fs-public/2014_12_a_plan_for_growing sydney.pdf.

Oke, T. R., 1981: Canyon geometry and the nocturnal urban heat island: Comparison of scale model and field observations. J. Climatol., 1, 237-254, https://doi.org/10.1002/ joc.3370010304.

_ 1982: The energetic basis of the urban heat island. Quart. J. Roy. Meteor. Soc., 108, 1-24, https://doi.org/10.1002/qj.49710845502. 2002: Boundary Layer Climates. Routledge, 464 pp. 2004: Initial guidance to obtain representative meteorological observations at urban sites. WMO/TD-1250, IOM Rep. 81, 51 pp., http://library.wmo.int/pmb_ged/wmo-td_ 1250.pdf. 
Pielke, R. A., R. Mahmood, and C. McAlpine, 2016: Land's complex role in climate change. Phys. Today, 69, 40-46, https://doi.org/10.1063/PT.3.3364.

Potchter, O., P. Cohen, and A. Bitan, 2006: Climatic behavior of various urban parks during hot and humid summer in the Mediterranean city of Tel Aviv, Israel. Int. J. Climatol., 26, 1695-1711, https://doi.org/10.1002/joc.1330.

Ramakrishnan, S., X. Wang, J. Sanjayan, and J. Wilson, 2016: Thermal performance of buildings integrated with phase change materials to reduce heat stress risks during extreme heatwave events. Appl. Energy, 194, 410-421, https://doi.org/10.1016/ j.apenergy.2016.04.084.

Ren, Z., X. Wang, D. Chen, C. Wang, and M. Thatcher, 2014: Constructing weather data for building simulation considering urban heat island. Build. Serv. Eng. Res. Tech., 35, 69-82, https:// doi.org/10.1177/0143624412467194.

Roth, M., 2007: Review of urban climate research in (sub)tropical regions. Int. J. Climatol., 27, 1859-1873, https://doi.org/10.1002/ joc.1591.

Rotstayn, L. D., 1997: A physically based scheme for the treatment of stratiform clouds and precipitation in large-scale models. I: Description and evaluation of the microphysical processes. Quart. J. Roy. Meteor. Soc., 123, 1227-1282, https://doi.org/ 10.1002/qj.49712354106.

Sakakibara, Y., 1996: A numerical study of the effect of urban geometry upon the surface energy budget. Atmos. Environ., 30, 487-496, https://doi.org/10.1016/1352-2310(94)00150-2.

Schrijvers, P. J. C., H. J. J. Jonker, S. Kenjereš, and S. R. de Roode, 2015: Breakdown of the night time urban heat island energy budget. Build. Environ., 83, 50-64, https://doi.org/10.1016/j. buildenv.2014.08.012.

Schwarzkopf, M. D., and S. B. Fels, 1991: The simplified exchange method revisited: An accurate, rapid method for computation of infrared cooling rates and fluxes. J. Geophys. Res., 96, 90759096, https://doi.org/10.1029/89JD01598.

, and V. Ramaswamy, 1999: Radiative effects of $\mathrm{CH}_{4}, \mathrm{~N}_{2} \mathrm{O}$, halocarbons and the foreign-broadened $\mathrm{H}_{2} \mathrm{O}$ continuum: A GCM experiment. J. Geophys. Res., 104, 9467-9488, https:// doi.org/10.1029/1999JD900003.

Scott, A. A., D. W. Waugh, and B. F. Zaitchik, 2018: Reduced Urban Heat Island intensity under warmer conditions. Environ. Res. Lett., 13, 064003, https://doi.org/10.1088/1748-9326/ aabd6c.

Seto, K. C., M. Fragkias, B. Güneralp, and M. K. Reilly, 2011: A meta-analysis of global urban land expansion. PLOS ONE, 6 , e23777, https://doi.org/10.1371/journal.pone.0023777.

_ - B. Güneralp, and L. R. Hutyra, 2012: Global forecasts of urban expansion to 2030 and direct impacts on biodiversity and carbon pools. Proc. Natl. Acad. Sci. USA, 109, 1608316088 , https://doi.org/10.1073/pnas.1211658109.
Sharifi, E., and S. Lehmann, 2014: Comparative analysis of surface urban heat island effect in central Sydney. J. Sustain. Dev., 7, 23-34, https://doi.org/10.5539/jsd.v7n3p23.

Spronken-Smith, R. A., and T. R. Oke, 1998: The thermal regime of urban parks in two cities with different summer climates. Int. J. Remote Sens., 19, 2085-2104, https://doi.org/10.1080/ 014311698214884.

$\longrightarrow$, and - 1999: Scale modelling of nocturnal cooling in urban parks. Bound.-Layer Meteor., 93, 287-312, https://doi.org/ 10.1023/A:1002001408973.

Stewart, I. D., 2011: A systematic review and scientific critique of methodology in modern urban heat island literature. Int. J. Climatol., 31, 200-217, https://doi.org/10.1002/joc.2141.

Sun, T., C. S. B. Grimmond, and G.-H. Ni, 2016: How do green roofs mitigate urban thermal stress under heat waves? J. Geophys. Res. Atmos., 121, 5320-5335, https://doi.org/10.1002/ 2016JD024873.

Thatcher, M., and P. Hurley, 2012: Simulating Australian urban climate in a mesoscale atmospheric numerical model. Bound. Layer Meteor., 142, 149-175, https://doi.org/10.1007/s10546011-9663-8.

Trewin, B., 2013: A daily homogenized temperature data set for Australia. Int. J. Climatol., 33, 1510-1529, https://doi.org/ 10.1002/joc. 3530 .

Unger, J., 2009: Connection between urban heat island and sky view factor approximated by a software tool on a 3D urban database. Int. J. Environ. Pollut., 36, 59-80, https://doi.org/ 10.1504/IJEP.2009.021817.

Ward, K., S. Lauf, B. Kleinschmit, and W. Endlicher, 2016: Heat waves and urban heat islands in Europe: A review of relevant drivers. Sci. Total Environ., 569-570, 527-539, https://doi.org/ 10.1016/j.scitotenv.2016.06.119.

Wienert, U., and W. Kuttler, 2005: The dependence of the urban heat island intensity on latitude-A statistical approach. Meteor. Z., 14, 677-686, https://doi.org/10.1127/0941-2948/2005/0069.

Wilby, R. L., 2008: Constructing climate change scenarios of urban heat island intensity and air quality. Environ. Plann., 35B, 902-919, https://doi.org/10.1068/b33066t.

Yow, D. M., 2007: Urban heat islands: Observations, impacts, and adaptation. Geogr. Compass, 1, 1227-1251, https://doi.org/ 10.1111/j.1749-8198.2007.00063.x.

Yunusa, I. A. M., D. Eamus, D. Taylor, R. Whitley, W. Gwenzi, A. R. Palmer, and Z. Li, 2015: Partitioning of turbulent flux reveals contrasting cooling potential for woody vegetation and grassland during heat waves. Quart. J. Roy. Meteor. Soc., 141, 2528-2537, https://doi.org/10.1002/qj.2539.

Zhou, W., J. Wang, and M. L. Cadenasso, 2017: Effects of the spatial configuration of trees on urban heat mitigation: A comparative study. Remote Sens. Environ., 195, 1-12, https:// doi.org/10.1016/j.rse.2017.03.043. 